\title{
Determination of the size of the Representative Volume Element (RVE) for the simulation of heterogeneous polymers at finite strains
}

Citation for published version (APA):

Mirkhalaf, S. M., Andrade Pires, F. M., \& Simoes, R. (2016). Determination of the size of the Representative Volume Element (RVE) for the simulation of heterogeneous polymers at finite strains. Finite Elements in Analysis and Design, 119, 30-44. https://doi.org/10.1016/j.finel.2016.05.004

DOI:

10.1016/j.finel.2016.05.004

Document status and date:

Published: 01/01/2016

Document Version:

Typeset version in publisher's lay-out, without final page, issue and volume numbers

Please check the document version of this publication:

- A submitted manuscript is the version of the article upon submission and before peer-review. There can be important differences between the submitted version and the official published version of record. People interested in the research are advised to contact the author for the final version of the publication, or visit the $\mathrm{DOI}$ to the publisher's website.

- The final author version and the galley proof are versions of the publication after peer review.

- The final published version features the final layout of the paper including the volume, issue and page numbers.

Link to publication

\footnotetext{
General rights

- You may freely distribute the URL identifying the publication in the public portal. follow below link for the End User Agreement:

www.tue.nl/taverne

Take down policy

If you believe that this document breaches copyright please contact us at:

openaccess@tue.nl

providing details and we will investigate your claim.
}

Copyright and moral rights for the publications made accessible in the public portal are retained by the authors and/or other copyright owners and it is a condition of accessing publications that users recognise and abide by the legal requirements associated with these rights.

- Users may download and print one copy of any publication from the public portal for the purpose of private study or research.

- You may not further distribute the material or use it for any profit-making activity or commercial gain

If the publication is distributed under the terms of Article 25fa of the Dutch Copyright Act, indicated by the "Taverne" license above, please 


\title{
Determination of the size of the Representative Volume Element (RVE) for the simulation of heterogeneous polymers at finite strains
}

\begin{abstract}
A B S T R A C T
The definition of the size of the Representative Volume Element (RVE) is extremely important for the mechanics and physics of heterogeneous materials since it should statistically represent the microstructure of the material. In the present contribution, a methodology based on statistical analysis and numerical experiments is proposed to determine the size of the RVE for heterogeneous amorphous polymers subjected to finite deformations. The approach is applied to Rubber Toughened Polystyrene (RT-PS) composed by a two phase random micro-structure. Different micro-structural samples with two different percentages of rubbery particles, namely $10 \%$ and $15 \%$, inside the micro-structure are studied. Periodic boundary conditions (PBC) are enforced to the RVE due to their fast convergence to the theoretical/effective solution when the RVE size increases. The Finite Element Method (FEM) is used in combination with mathematical homogenization to obtain the macro-stress. Two criteria are proposed for the RVE size determination. The proposed statistical-numerical approach is general and easy to use, when compared to the previously proposed approaches, and covers other criteria available in the literature.
\end{abstract}

(c) 2016 Elsevier B.V. All rights reserved.

\section{Introduction}

Polymers have attracted a considerable attention from both academic and industrial communities due to their interesting characteristics such as good thermal and electrical insulation, lower density and also usually higher yield strain when compared to metals [1]. Besides the properties mentioned above, one of the relevant features of polymers is that complicated shapes can be easily fabricated through processes such as extrusion, injection molding and casting. For these reasons, polymers have a variety of applications, which are far more than any other class of materials, such as electronic products, automotive engineering, bio-mechanics, civil and building engineering, among others.

In spite of very interesting properties, polymeric materials also have some undesirable characteristics. For instance, glassy polymers show brittleness under specific conditions. Polystyrene (PS) and Polymethylmethacrylate (PMMA), among other glassy polymers, are considered brittle since they show brittle failure under low stress triaxiality such as uniaxial tension [2]. Therefore, in order to take advantage of the mentioned qualities of polymers and also improving the unfavourable characteristics, polymer

\footnotetext{
* Corresponding author.

E-mail address: fpires@fe.up.pt (F.M. Andrade Pires).
}

based composite materials have been the focus of a large number of studies during the last decade.

The most widely used strategy to improve the mechanical properties of materials consists in directly modifying the microstructure of the material, see e.g. [3], which usually promotes a more heterogeneous nature including different phases in the micro-structure. Therefore, it becomes vital to establish relationships between the micro-structure of the material and the engendered macroscopic properties. There are different approaches to characterize the behaviour of materials with heterogeneous micro-structures. One possible approach is to fit material properties to experimental results for a continuum level constitutive model (e.g. [4]). Another approach consists in changing a continuum level constitutive model by including some information from the micro-structure of the material into the constitutive equations of the model so that the model could characterize the behaviour of the material with modified micro-structure (e.g. [2]). The most recent strategy entails the use of micro-mechanical or coupled multi-scale models based on homogenization techniques to transfer information between different scales (e.g. [5,6]). In fact, different homogenization techniques are used by different authors in order to model the mechanical behaviour of heterogeneous materials (see e.g. [7-10]). The reader is referred to [11] for a comprehensive review on homogenization techniques. 
In order to work within the framework of micro-mechanical and coupled multi-scale approaches, it is required to have the Representative Volume Element (RVE) of the heterogeneous material defined. In published literature, there are different definitions for the RVE (see e.g. [12-18]). What is common in the variety of definitions is that the RVE should accommodate enough information about the micro-structure, while its dimensions are smaller than the macroscopic dimensions, so that the concept of separation of scales is satisfied.

During the last two decades, there have been different methods employed by the scientific community to determine the RVE size (RVES) from image processing approaches (e.g. [19-21]), experimental-image processing methods (e.g. [22]), analytical approaches (e.g. $[13,23])$ and statistical-numerical methods (e.g. [24-29]). Grimal et al. [19] have derived the field of elastic coefficients from one acoustic microscopy image of a human femur cortical bone sample with an overall porosity of $8.5 \%$. They have also used FEM to obtain the homogenized properties of RVEs. Shan and Gokhale [20] have introduced a methodology involving image analysis techniques for determination of the RVES for Ceramic Matrix Composites (CMC) with different fiber sizes. Graham and Yang [21] determined the RVES for HY-100 steel using image analysis of the polished cross section of the material. Romero and Masad [22] have obtained the RVES for an asphalt concrete specimen utilizing an image analysis approach and they have verified their results with some mechanical tests. Drugan and Willis [13] employed a variational formulation to derive a nonlocal constitutive equation for a class of random linear elastic composite materials. They have estimated the RVES by comparing the magnitude of the non-local term and the portion of the equation that relates ensemble average stresses and strains through a constant "overall" modulus tensor. Sebsadji and Chouicha [23] have proposed an analytical approach, using fractal analysis, to obtain the RVES for concrete mixtures. Kanit et al. [24] have performed a statistical analysis of the numerical examples in order to quantify the RVES for two-phase three-dimensional Voronoii mosaic in the case of linear elasticity and thermal conductivity. Kanit et al. [25] have extended the statistical-numerical approach introduced in the previous work by Kanit et al. [24] to the case of real microstructures of two materials from the food industry for RVES determination. Pelissou et al. [26] have started from the work of Kanit et al. [24] and introduced a new approach for RVES determination for a metal matrix composite with randomly distributed aligned brittle inclusions. Skarzynski and Tejchman [27] have used two different approaches, within a statistical analysis, to determine the RVES for softening quasi-brittle materials. The first approach, failure zone averaging approach, was previously introduced by Nguyen et al. [30]. Gitman et al. [28] investigated RVE existence in different stages of loading, elastic-hardening-softening, and also proposed a method to determine the RVES for random three-phase (matrix, inclusion and ITZ) heterogeneous materials. Stroeven et al. [29] have used different criteria (peak load, dissipated energy, strain concentration factor), within a statistical-numerical framework to determine RVES for materials with particles in a matrix material.

In this contribution, a statistical-numerical approach is proposed to determine the RVES for heterogeneous amorphous polymers subjected to finite deformations. Polystyrene (PS) is used as the matrix material toughened with rubbery particles. Two different volume fraction of inclusions are considered. The paper is structured as follows. Section 2 presents the kinematics of the micro-scale problem. The material model used for the polymeric matrix material is presented in Section 3. Section 4 presents some numerical examples at the micro-structural level with different percentage of inclusion volume fraction of rubbery particles. Section 5 details the proposed statistical-numerical approach for determination of the RVES which is illustrated with numerical examples. Finally, Section 6 is devoted to some conclusions and concluding remarks.

\section{Kinematics of the micro-scale problem}

In this section, the mathematical formulation and main kinematical assumptions governing this study will be introduced. If $\mathbf{x}$ is an infinitesimal point at the macro-scale, $\mathbf{y}$ is an infinitesimal point on the RVE domain and $\mathbf{T}(\mathbf{y})$ is a generic field defined over the RVE domain, the homogenized response of the field, $\mathbf{T}$, for the macroscopic point to which the RVE is linked, is obtained by the following volume average relation:

$\mathbf{T}(\mathbf{x})=\frac{1}{V} \int_{\Omega} \mathbf{T}(\mathbf{y}) d V$,

where $V$ is the RVE volume and $\Omega$ is the RVE domain. It must be emphasized that the above relation can be applied to both undeformed and deformed configurations of the RVE. In this study, all the homogenized variables are defined as the volume average of the respective quantities over the initial configuration of the RVE.

The deformation of the RVE is driven by the macroscopic deformation gradient, which is the volume average of the microscopic deformation gradient:

$\mathbf{F}(\mathbf{x}, t)=\frac{1}{V_{0}} \int_{\Omega} \mathbf{F}(\mathbf{y}, t) d V$.

The microscopic deformation gradient is given by:

$\mathbf{F}(\mathbf{y}, t)=\mathbf{I}+\nabla_{p} \mathbf{u}(\mathbf{y}, t)$,

where I is the second order identity tensor, $\mathbf{u}(\mathbf{y}, t)$ is the displacement field at micro-scale and $\nabla_{p}(*)$ is the material gradient operator. Using relations (2) and (3), the macroscopic deformation gradient is given by:

$\mathbf{F}(\mathbf{x}, t)=\mathbf{I}+\frac{1}{V_{0}} \int_{\Omega} \nabla_{p} \mathbf{u}(\mathbf{y}, t) d V$.

The displacement field at the micro-scale can be split into two terms:

$\mathbf{u}(\mathbf{y}, t)=[\mathbf{F}(\mathbf{x}, t)-\mathbf{I}] \mathbf{Y}+\tilde{\mathbf{u}}(\mathbf{y}, t)$,

where the first term is the linear displacement varying linearly with $\mathbf{Y}$, which represents the RVE coordinates in the reference configuration, and the second term denoted by $\tilde{\mathbf{u}}(\mathbf{y}, t)$ is the displacement fluctuation field. Using Eqs. (3) and (5), the microscopic deformation gradient, $\mathbf{F}(\mathbf{y}, t)$, can be expressed as:

$\mathbf{F}(\mathbf{y}, t)=\mathbf{F}(\mathbf{x}, t)+\nabla_{p} \tilde{\mathbf{u}}(\mathbf{y}, t)$.

Doing some algebraic manipulations, using divergence theorem and relations (2) and (6), results in the minimal kinematical admissible constraint:

$\int_{\partial \Omega} \tilde{\mathbf{u}}(\mathbf{y}, t) \otimes \mathbf{N}(\mathbf{Y}) d A=0$

where $\mathbf{N}(\mathbf{Y})$ denotes the outward unit vector to the undeformed boundary of the RVE. The virtual work equilibrium of the RVE states that:

$$
\begin{gathered}
\int_{\Omega} \mathbf{P}(\mathbf{y}, t): \nabla \boldsymbol{\eta} d V-\int_{\Omega} \mathbf{B}^{r e f}(\mathbf{y}, t) \cdot \boldsymbol{\eta} d V-\int_{\partial \Omega} \mathbf{T}^{r e f}(\mathbf{y}, t) \\
\cdot \boldsymbol{\eta} d A=0 \quad \forall \boldsymbol{\eta} \in \nu,
\end{gathered}
$$

where $\mathbf{B}^{\text {ref }}(\mathbf{y}, t)$ and $\mathbf{T}^{\text {ref }}(\mathbf{y}, t)$ are respectively the reference body force and the reference boundary traction force of the RVE. The symbol $\nu$ denotes the space of the virtual admissible displacement fluctuation field $\boldsymbol{\eta}$. The first Piola-Kirchhoff stress of the infinitesimal point at the macro-scale is the volume average of 
corresponding stress at the micro-scale:

$\mathbf{P}(\mathbf{x}, t)=\frac{1}{V_{0}} \int_{\Omega} \mathbf{P}(\mathbf{y}, t) d V$.

In order to relate the micro-scale and macro-scale, the HillMandel principle is used. This principle is expressed as follows:

$\mathbf{P}(\mathbf{x}, t): \dot{\mathbf{F}}(\mathbf{x}, t)=\frac{1}{V_{0}} \int_{\Omega} \mathbf{P}(\mathbf{y}, t): \dot{\mathbf{F}}(\mathbf{y}, t) d V$,

which states equality between the macroscopic stress power and volume average of microscopic stress power over the RVE domain. The Hill-Mandel principle can be equivalently written as:

$\int_{\partial \Omega} \mathbf{T}^{r e f}(\mathbf{y}, t) \cdot \dot{\tilde{\mathbf{u}}}(\mathbf{y}, t) d A=0$,

$$
\int_{\Omega} \mathbf{B}^{r e f}(\mathbf{y}, t) \cdot \dot{\tilde{\mathbf{u}}}(\mathbf{y}, t) d V=0
$$

\subsection{Periodic boundary condition}

The periodic boundary condition (PBC) is the most commonly adopted kinematical boundary constraint for the solution of RVE equilibrium problem. It has been demonstrated that PBC converges faster to the effective (or theoretical) as the RVE size increases $[24,31]$. In other words, for the same RVE size, PBC gives a better estimation of the effective properties in comparison to the other boundary conditions. This boundary condition is particularly suitable for the analysis of the mechanical behaviour of materials with periodic or even quasi-periodic microstructure. This boundary condition assumes that the boundary of the RVE is composed of negative and positive parts:

$\partial \Omega=\left(\Gamma_{i}^{-} \cup \Gamma_{i}^{+}\right)$,

where each point $y^{+} \in \Gamma_{i}^{+}$has a counterpart point $y^{-} \in \Gamma_{i}^{-}$. Fur-

$n^{+}=-n^{-}$,

where $n^{+}$and $n^{-}$are the unit normal vectors of $\Gamma_{i}^{+}$and $\Gamma_{i}^{-}$at points $y^{+}$and $y^{-}$, respectively. The displacement fluctuation field for periodic boundary condition is periodic:

$\tilde{\mathbf{u}}\left(\mathbf{y}^{+}, t\right)=\tilde{\mathbf{u}}\left(\mathbf{y}^{-}, t\right)$,

and the traction field is anti-periodic:

$\mathbf{T}^{r e f}\left(\mathbf{y}^{+}, t\right)=-\mathbf{T}^{r e f}\left(\mathbf{y}^{-}, t\right)$

Therefore, the application of PBC on the RVE consists in the enforcement of an identical fluctuation field for each pair of corresponding boundaries of the RVE. This forces the RVE to be discretized with a conform mesh. Nevertheless, in order to apply periodic boundary conditions on arbitrary finite element mesh discretization, several strategies have been proposed (e.g. [32-34]).

A comprehensive account of the numerical aspects required for the computational implementation of multi-scale constitutive models within a generic non-linear implicit finite element framework at finite strains can be found in [35], among others. thermore, the following condition must be satisfied:

\section{Material model}

Over the last century, a considerable effort has been devoted to the development of new material models capable of reproducing experimentally observed data. It can be said that the initiation of the efforts to determine the behaviour of polymers dates back to 1930s. Eyring [36] proposed a molecular theory for the yield stress of amorphous polymers. Later, Mooney [37] proposed a strain energy function for rubber elastic materials. Haward and Tackray [38] developed a one dimensional constitutive model for glassy polymers and Boyce et al. [39] established a three dimensional version of Haward and Tackray model. Another constitutive approach that has been introduced to characterize the deformation behaviour of polymers is the generalized compressive Leonov model (currently known as EGP model). This model has been proposed by Baaijens [40] and extended by Tervoort et al. [41] and Govaert et al [42]. In addition to the models developed to characterize the behaviour of polymers at continuum level, some authors have devoted their work to predict the deformation behaviour of polymers using molecular dynamics simulations (see e.g. $[43,44])$ or through multi-scale models from the molecular structure to the macro-scale (see e.g. [45]).

This section briefly describes the elasto-viscoplastic constitutive model which is used in this study. The total deformation gradient, $\mathbf{F}$, is multiplicatively composed of the elastic deformation gradient, $\mathbf{F}^{e}$, and the plastic deformation gradient, $\mathbf{F}^{p}$, [46]:

$\mathbf{F}=\mathbf{F}^{e} \mathbf{F}^{p}$

It should be emphasized that the aforementioned decomposition of the deformation gradient has been mainly attributed to Lee [47] but recently Sadik and Yavari [48] showed that the decomposition was first introduced by Bilby et al. [46]. To measure the elastic deformations, the logarithmic (or natural) Eulerian (or spatial) strain is adopted. The plastic flow rule of the model is characterized by the generalized Eyring equation, which is given by:

$\mathbf{d}^{p}=\dot{\gamma}^{e q} \frac{\partial \Psi}{\partial \boldsymbol{\tau}}=\dot{\gamma}^{e q} \mathbf{N}$,

where $\dot{\gamma}^{e q}$ is the equivalent rate of shear strain, $\boldsymbol{\tau}$ is the Kirchhof stress tensor, $\Psi$ is the dissipation potential, $\mathbf{N}$ is the flow vector and $\mathbf{d}^{p}$ is the spatial plastic stretching tensor. The dissipation potential of the model is assumed to be given by:

$\Psi=\sqrt{\frac{1}{2} \mathbf{s}: \mathbf{s}}$

Consequently, the flow vector is obtained as:

$\mathbf{N}=\frac{\partial \Psi}{\partial \boldsymbol{\tau}}=\sqrt{\frac{1}{2\|\mathbf{S}\|}}$,

where $\|\mathbf{s}\|$ is the norm of $\mathbf{s}$ which is given by:

$\|\mathbf{S}\|=\sqrt{\mathbf{S}: \mathbf{S}}$

Combining relations (18) and (20), the multi-dimensional plastic flow rule of the model is obtained as:

$\mathbf{d}^{p}=\dot{\gamma}^{e q} \sqrt{\frac{1}{2\|\mathbf{s}\|}}$.

Table 1

6 Material properties for PS required by the constitutive model.

\begin{tabular}{|c|c|c|c|c|c|c|c|c|c|c|}
\hline & $E(\mathrm{MPa})$ & $\nu$ & $\Delta H(\mathrm{~J} / \mathrm{mol})$ & $A_{0}(\mathrm{~s})$ & $\tau_{0}(\mathrm{MPa})$ & $D_{\infty}$ & $h$ & $\mu$ & $R$ & $H(\mathrm{MPa})$ \\
\hline PS & 3300 & 0.37 & $1.7 \mathrm{E}+5$ & $1.11 \mathrm{E}-20$ & 2.559 & 9 & 60 & 0.14 & 8.3143 & 11 \\
\hline
\end{tabular}




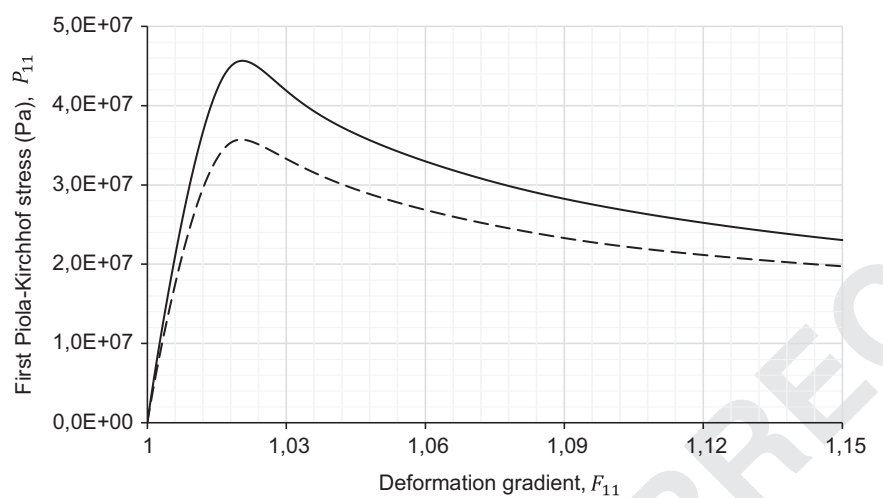

Fig. 2. Stress-deformation of the samples shown in Fig. 1, solid line: $10 \%$ and dashed line: $15 \%$.

The equivalent rate of shear strain is given by:

$\dot{\gamma}^{e q}=\frac{1}{A} \sinh \left(\frac{\tau^{e q}}{\tau_{0}}\right)$,

where $\tau^{e q}$ is an equivalent stress defined by:

$\tau^{e q}=\sqrt{\frac{1}{2} \operatorname{tr}(\mathbf{s S})}=\sqrt{\frac{1}{2} \mathbf{s}: \mathbf{s},}$

where $\mathbf{s}$ is the deviatoric stress. Using relation (23) and also Eq. (24), the plastic flow rule can be expressed in another form:

$\mathbf{d}^{p}=\frac{1}{A} \sinh \left(\frac{\tau^{e q}}{\tau_{0}}\right)\left(\frac{\mathbf{s}}{2 \tau^{e q}}\right)$,

or equivalently,

$$
\mathbf{d}^{p}=\frac{\mathbf{s}}{2 A\left[\frac{\tau^{e q}}{\sinh \left(\tau^{e q} / \tau_{0}\right)}\right]},
$$

which can be represented as:

$\mathbf{d}^{p}=\frac{\mathbf{s}}{2 \eta\left(\tau^{e q}\right)}$.

The viscosity function, $\eta\left(\tau^{e q}\right)$, is given by:

$\eta\left(\tau^{e q}\right)=A\left[\frac{\tau^{e q}}{\sinh \left(\tau^{e q} / \tau_{0}\right)}\right]$. b

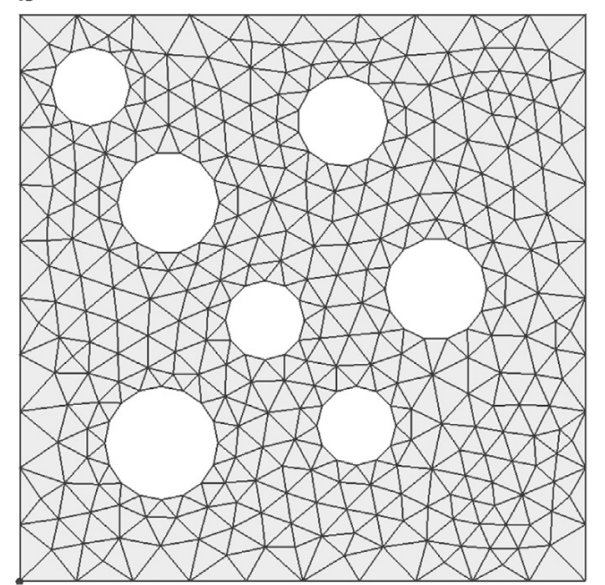

The rate of equivalent plastic shear can be expressed in terms of multi-dimensional plastic flow rule:

$\dot{\gamma}^{e q}=\sqrt{2 \mathbf{d}^{p}: \mathbf{d}^{p}}$.

The scalar parameter $A$ is given by:

$A=A_{0} \exp \left[\frac{\Delta H}{R T}+\frac{\mu P}{\tau_{0}}-D\right]$

where the scalar $A_{0}$ is a constant or pre-exponential factor involving the fundamental vibration energy; the parameter $\Delta H$ is the activation energy; the parameter $R$ is the universal gas constant; the scalar $T$ is the absolute temperature; the parameter $\mu$ is a pressure coefficient related to the shear activation volume, $V$, and the pressure activation volume, $\Omega$, according to:

$\mu=\frac{\Omega}{V}$.

The deformation behaviour of polymers is also dependent on the hydrostatic pressure and thus the hydrostatic pressure should take part in the constitutive relations of the material model. In relation (30), $P$ represents the total hydrostatic pressure of the analysis. The parameter $D$, in relation (30), is a softening parameter. The evolution of the softening parameter is modelled according to [49]:

$\dot{D}=h\left(1-\frac{D}{D_{\infty}}\right) \dot{\bar{\gamma}}^{p}$,

where $D_{\infty}$ is the saturation value of the softening parameter and $\dot{\bar{\gamma}}^{p}$ is an equivalent plastic strain rate defined by [42]:

$\dot{\bar{\gamma}}^{p}=\sqrt{\mathbf{d}^{p}: \mathbf{d}^{p}}$

Using relations (24), (28)-(30) and (32) together with some algebraic manipulations results in the following viscosity function:

$\eta=A_{0} \exp \left[\frac{\Delta H}{R T}+\frac{\mu P}{\tau_{0}}-D_{\infty}+D_{\infty} \exp \left(\frac{-h \sqrt{3} \bar{\varepsilon}^{p}}{\sqrt{2} D_{\infty}}\right)\right]\left[\tau^{e q} / \sinh \left(\frac{\tau^{e q}}{\tau_{0}}\right)\right]$,

where $\bar{\varepsilon}^{p}$ is the accumulated plastic strain. The accumulated plastic strain rate is defined by:

$\dot{\bar{\varepsilon}}^{p}=\sqrt{\frac{2}{3} \dot{\boldsymbol{\varepsilon}}^{p}}: \dot{\boldsymbol{\varepsilon}}^{p}$.

The total stress, $\boldsymbol{\tau}^{\text {total }}$, is additively composed of driving stress, $\boldsymbol{\tau}^{\text {driving, }}$, and hardening stress $\boldsymbol{\tau}^{\text {hardening }}$ :

$\boldsymbol{\tau}^{\text {total }}=\boldsymbol{\tau}^{\text {driving }}+\boldsymbol{\tau}^{\text {hardening }}$ 
a

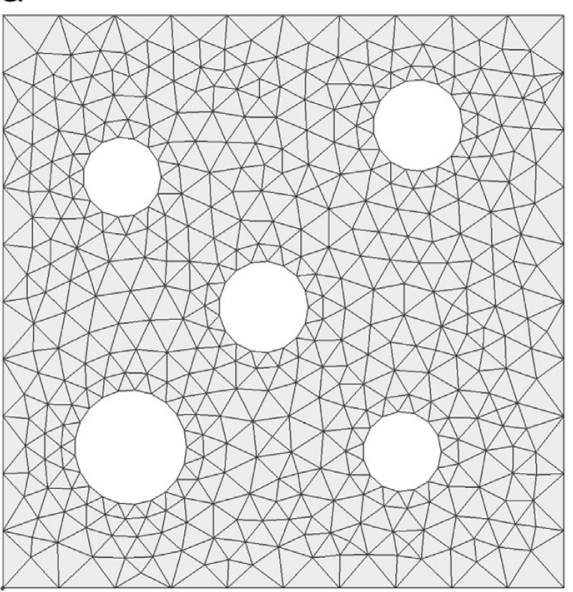

b

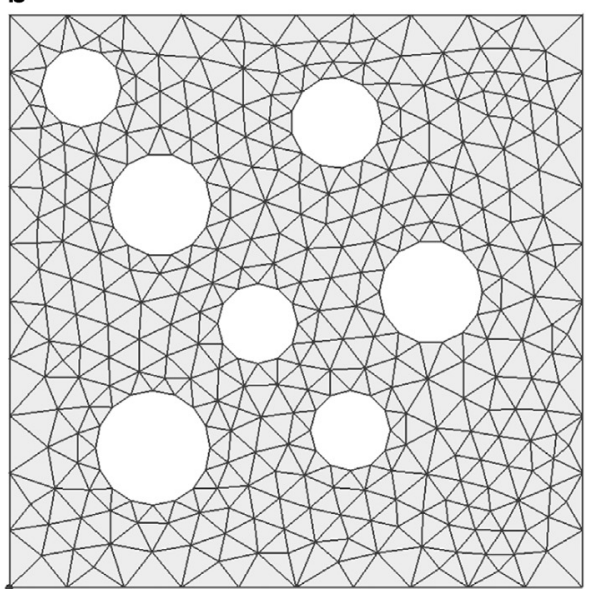

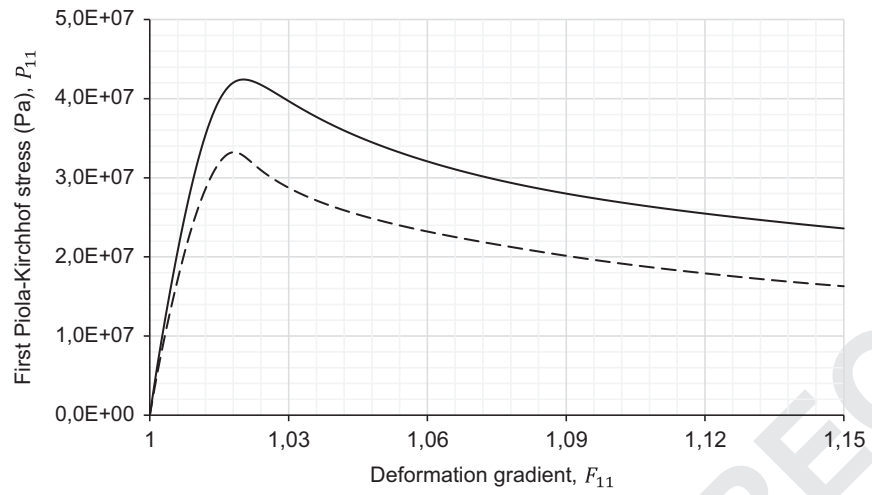

Fig. 4. Stress-deformation of the samples shown in Fig. 3, solid line: $10 \%$ and dashed line: $15 \%$.

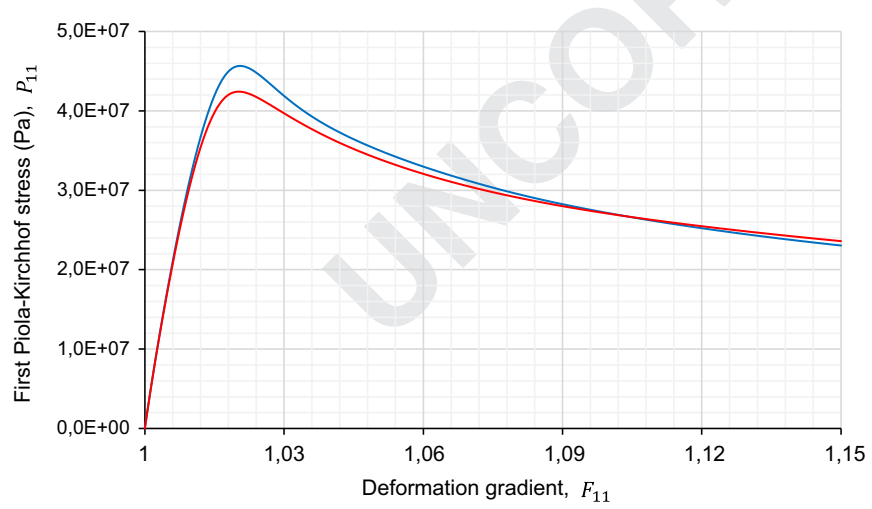

Fig. 5. Stress-deformation of the samples shown in Figs. 1(a) and 3(a), both with inclusion volume fraction equal to 10\%: blue line Fig. 1(a) and red line Fig. 3(a). (For interpretation of the references to colour in this figure caption, the reader is 5 referred to the web version of this paper.)

In this model, the hardening stress is given as the deviatoric strain multiplied by a hardening modulus:

$\boldsymbol{\tau}^{\text {hardening }}=H \boldsymbol{\varepsilon}_{d}$,

where $\boldsymbol{\varepsilon}_{d}$ gives the total deviatoric strain and $H$ is the hardening modulus, which is one of the material parameters. The deviatoric strain is given by:

$\boldsymbol{\varepsilon}_{d}=I_{d}: \boldsymbol{\varepsilon}$,

where $I_{d}$ is the fourth order deviatoric identity tensor.

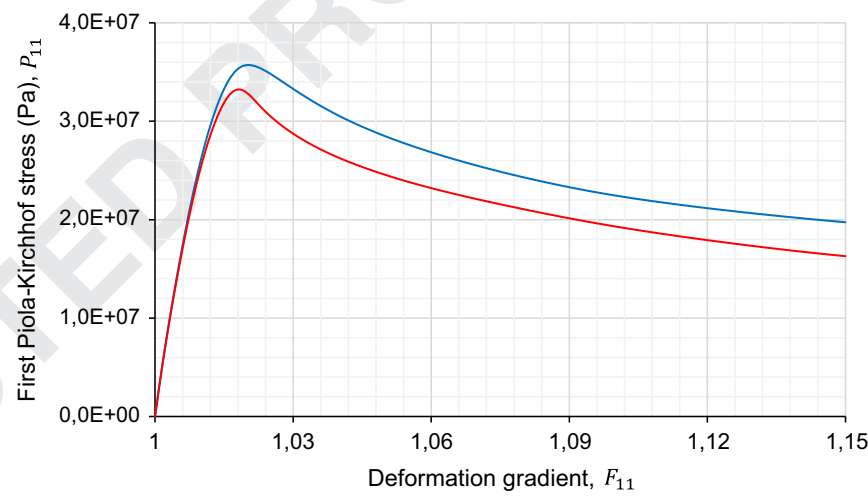

Fig. 6. Stress-deformation of the samples shown in Figs. 1(b) and 3(b), both with inclusion volume fraction equal to 15\%: Fig. 1(b) and red line: Fig. 3(b). (For interpretation of the references to colour in this figure caption, the reader is referred to the web version of this paper.)

For a more elaborate discussion on the constitutive model and also the integration algorithm and finite element implementation, the reader is referred to [50].

\section{Numerical examples}

In this section, some numerical examples are performed on samples of rubber toughened Polystyrene composed by two phases: Polystyrene (PS) and rubber. The material properties for PS are taken from van Melick et al. [52] and are given in Table 1. It should be mentioned that due to the deformation induced cavitation early during deformation [2], the rubbery particles are modelled as voids. Two levels of inclusion volume fraction, namely $10 \%$ and $15 \%$, are considered and the inclusions size range is assumed to be from $0.7 \mu \mathrm{m}$ to $1 \mu \mathrm{m}$.

Remark 1. The rubbery particles are chosen to be within the mentioned size range due to the fact that the rubber toughening process is normally performed using sub-micron sized rubbery particles [2,51].

The first sample size is $10 \mu \mathrm{m}$. The samples are analysed with a non-linear finite element framework at finite strains which contains the constitutive model described in Section 3. The numerical approach employed to analyse each micro-structural sample consists in enforcing a macroscopic deformation gradient, $\mathbf{F}$, to the RVE and solving the micro-scale equilibrium problem and then 
obtain the homogenized response of the stress field. The numerical simulations are performed under tensile loading conditions with the following deformation gradient:

$\mathbf{F}=\left[\begin{array}{cc}1.15 & 0 \\ 0 & 1\end{array}\right]$

Fig. 1 shows two samples with dimension of $10 \mu \mathrm{m}$ and volume fraction of inclusions equal to $10 \%$ and $15 \%$ that were randomly

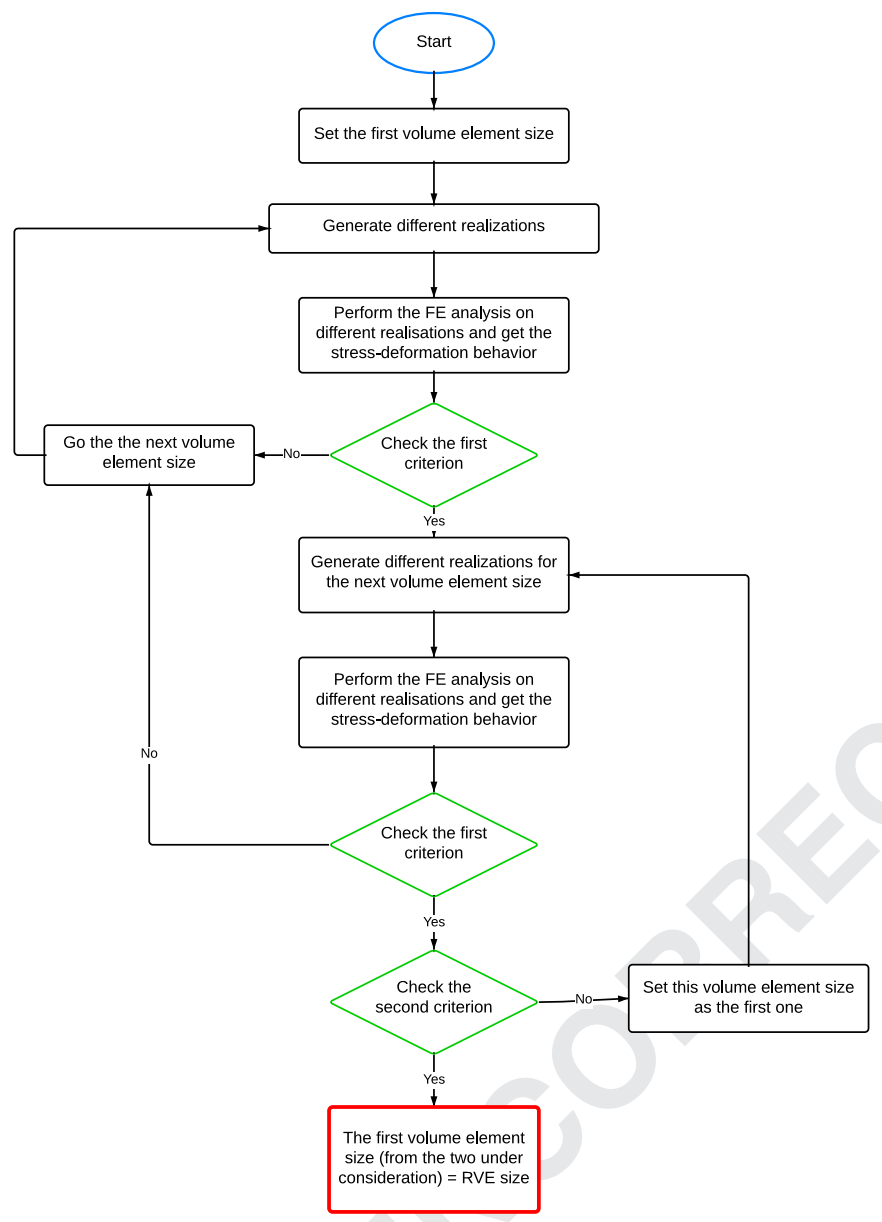

Fig. 7. Flow chart for RVES determination. generated. The standard six-noded plane strain triangular element, with three Gauss integration points, is adopted for the spatial discretization of the samples. The mesh discretization for both cases is defined such that the relevant features of the geometry are well captured without an excessive level of refinement with $\mathrm{PBC}$ enforced to the relevant edges. Fig. 2 shows the stress deformation for both samples subjected to tensile loading under periodic boundary conditions. As expected, the increase in the inclusion volume fraction from $10 \%$ to $15 \%$ leads to a significant decrease of the material response quantified by $P_{11}-F_{11}$ curve. In order to analyse the impact of changing the morphology of the micro-structure on the overall deformation behaviour, one more sample of each inclusion volume fraction is generated. The samples are shown in Fig. 3. Fig. 4 depicts the stress-deformation graph for the samples shown in Fig. 3. In order to directly compare the difference between different realizations of the same inclusion volume fraction, the stress-deformation graph for samples of the size of $10 \mu \mathrm{m}$ and inclusion volume fraction of $10 \%$, shown in Figs. 1(a) and 3(a), is shown in Fig. 5. Similar to Fig. 5, the stressdeformation graph for samples of the size of $10 \mu \mathrm{m}$ and inclusion volume fraction of 15\%, depicted in Figs. 1(b) and 3(b), is presented in Fig. 6. As can be seen in Figs. 5 and 6, changing the morphology of the micro-structure clearly affects the overall behaviour of the micro-structural samples. Therefore, it is necessary to define what is the appropriate RVE size for each volume fraction of inclusions, such that the results obtained can be regarded as representative. To achieve this, a combined numerical-statistical analysis is proposed in Section 5, where two criteria are introduced for the determination of the RVE size.

\section{RVE size}

As mentioned before, working within the framework of micromechanical modelling and coupled multi-scale modelling approaches requires an appropriate definition of the RVE. An RVE should be large enough to accommodate enough information from the material micro-structure and at the same time, small enough to comply with the separation of scales. In this section, a statistical procedure combined with numerical simulations to determine the RVES is presented. Again, Rubber Toughened Polystyrene (RT-PS) is considered for the numerical examples. Two different volume fraction of inclusions are considered namely $10 \%$ and $15 \%$. The initial

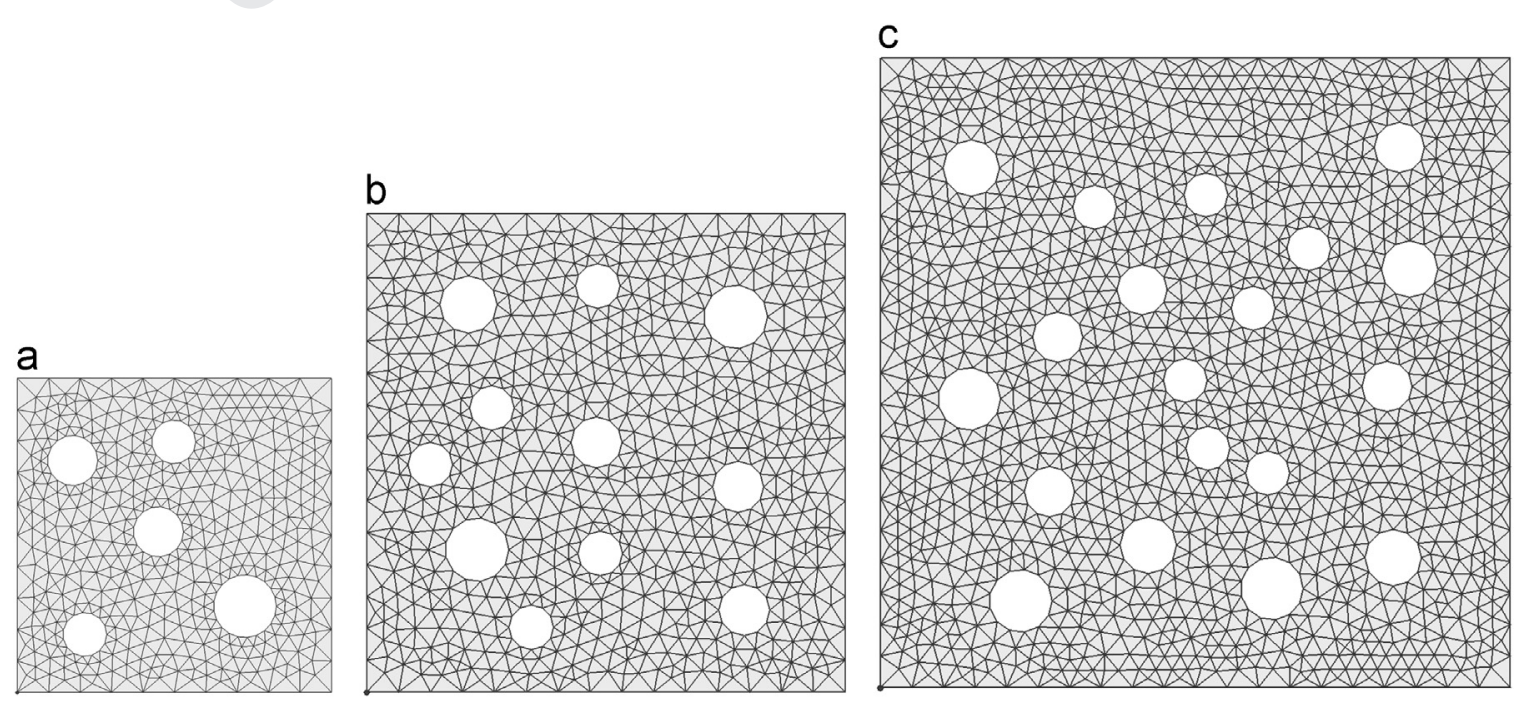




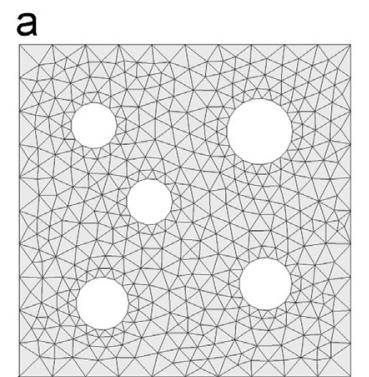

b

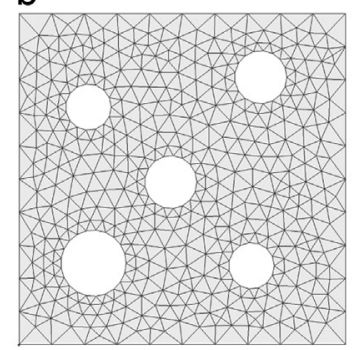

C

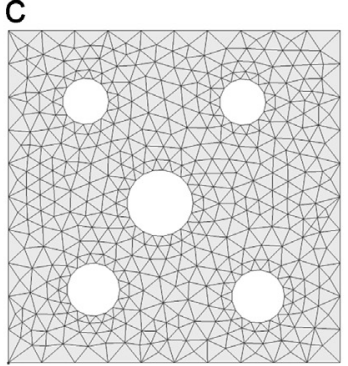

d

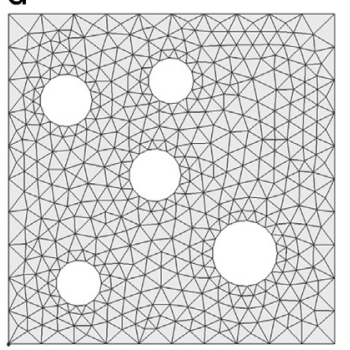

e

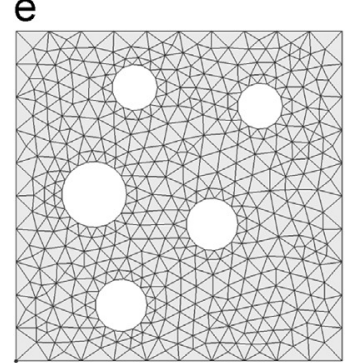

Fig. 9. Different realizations for inclusion volume fraction equal to $10 \%$ and volume element size equal to $10 \mu \mathrm{m}$.

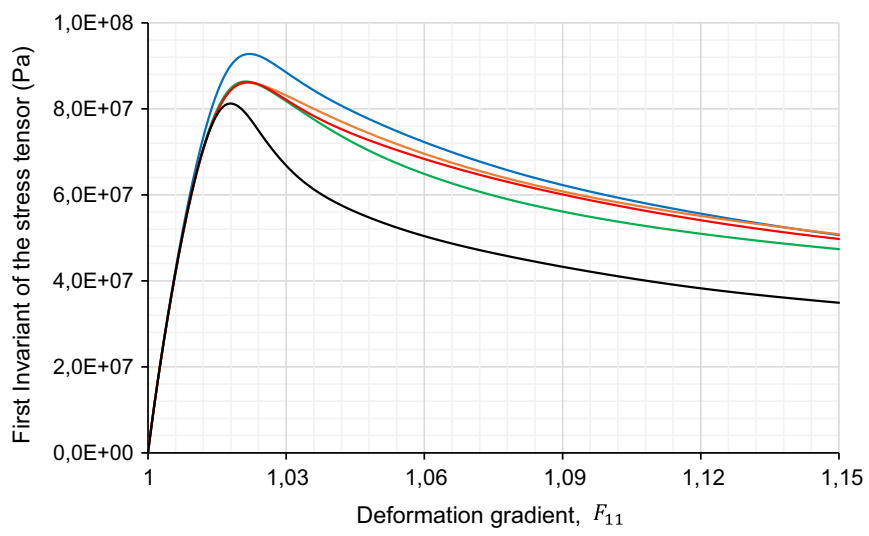

Fig. 10. Stress-deformation of the samples shown in Fig. 9: blue line: Fig. 9(a), orange line: Fig. 9(b), green line: Fig. 9(c), red line: Fig. 9(d), black line: Fig. 9(e). (For interpretation of the references to colour in this figure caption, the reader is referred to the web version of this paper.)

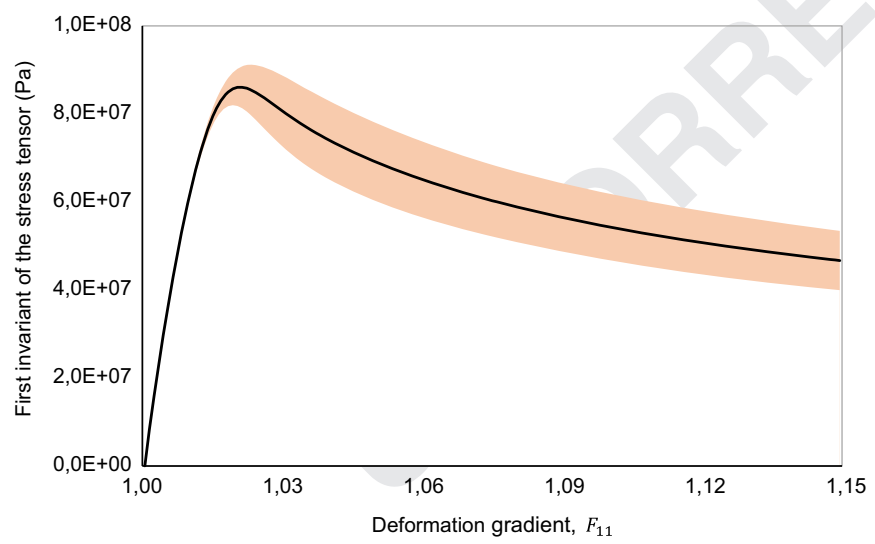

Fig. 11. Average stress-deformation of the samples shown in Fig. 9 with shaded bounds of standard deviation.

Table 2

The percentage of (standard deviation/average) for some representative values of deformation gradient for the samples shown in Fig. 9.

\begin{tabular}{lllllll}
\hline Deformation gradient, $F_{11}$ & 1,01 & 1,02 & 1,05 & 1,08 & 1,12 & 1,15 \\
\hline Standard deviation/average (\%) & 1.26 & 4.90 & 12.85 & 13.55 & 14.25 & 14.42 \\
\hline
\end{tabular}

volume element size is assumed to be $10 \mu \mathrm{m}$ and the inclusion size range is from $0.7 \mu \mathrm{m}$ to $1 \mu \mathrm{m}$.

The procedure for RVES determination is as follows. First, different distributions of one volume element size and inclusion volume fraction are generated. Then, the samples are loaded and the stress-deformation graphs are extracted. Two criteria are introduced in order to determine the RVES:
1. The standard deviation of the deformation behaviour, which is represented by a specific deformation measure, should not be more than a predefined percentage of average deformation behaviour. In this work, $10 \%$ is considered for the variation of the first invariant of the first Piola-Kirchhof stress tensor, $I_{1}(\mathbf{P})$. The criterion is given by:

$S_{I_{1}(\mathbf{P})}=\sqrt{\frac{1}{n-1} \sum_{i=1}^{n}\left(I_{1}^{i}(\mathbf{P})-\overline{I_{1}(\mathbf{P})}\right)^{2}} \leq\left(0.1 \times \overline{I_{1}(\mathbf{P})}\right)$

where $S_{I_{1}(\mathbf{P})}$ is the standard deviation, $n$ is the number of samples, $I_{1}^{i}(\mathbf{P})$ is the $i$ th value of the first invariant of the first PiolaKirchhof stress tensorand $\overline{I_{1}(\mathbf{P})}$ is the mean value which is given by:

$$
\overline{I_{1}(\mathbf{P})}=\sum_{i=1}^{n} \frac{I_{1}^{i}(\mathbf{P})}{n}
$$

Checking this criterion ensures that changing the realization, for the same sample size and same inclusion volume fraction, does not remarkably change the deformation behaviour.

2. The average behaviour of all the realisations of the same volume element size, $k$, denoted by ${\overline{I_{1}(\mathbf{P})}}^{k}$ is within a desirable predefined error with the average response of the next volume element size, $k+1$, denoted by ${\overline{I_{1}(\mathbf{P})}}^{k+1}$ :

$\operatorname{Error}(\%)=\frac{\left|{\overline{I_{1}(\mathbf{P})}}^{k+1}-{\overline{I_{1}(\mathbf{P})}}^{k}\right|}{{\overline{I_{1}(\mathbf{P})}}^{k+1}} \leq 10 \%$.

In this work, $10 \%$ is considered for the variation of the average first invariant of the first Piola-Kirchhof stress tensor of two consecutive volume element size. The second criterion checks if by increasing the size of the micro-structural sample, the deformation behaviour changes. If no considerable change is observed, while increasing the sample size, this criterion is satisfied.

The next stage is to check the first criterion to see whether it is satisfied. If the first criterion is satisfied, different distributions of the next volume element size with the same inclusion volume fraction are to be generated and analysed and the second criterion is checked. In case the second criterion is satisfied as well, the previous volume element size is RVES. If the first criterion is not satisfied, the next volume element size would be considered as the initial volume element size and the same process, as mentioned above, would be done. This procedure is represented in Fig. 7 .

Remark 2. The procedure suggested is basically a method for determining a numerical RVE size for a given heterogeneous 


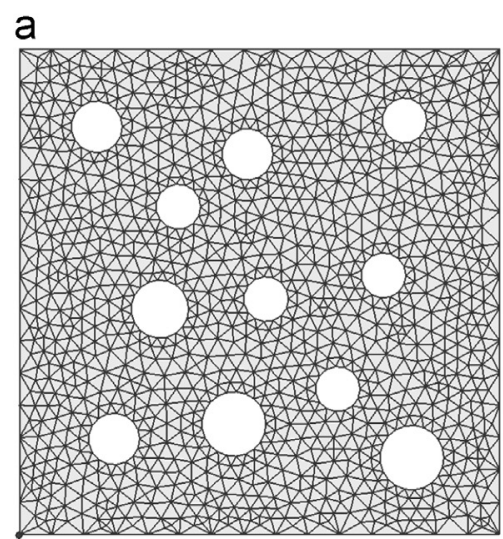

b

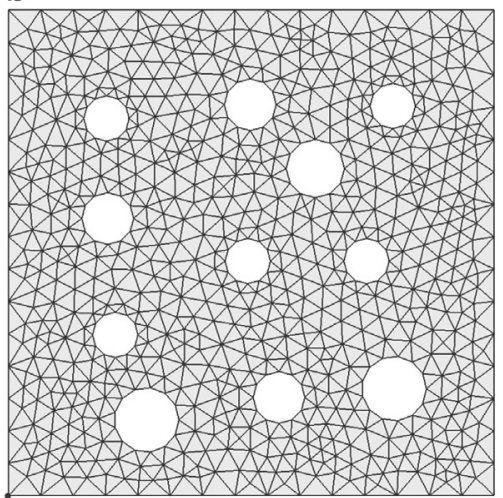

C

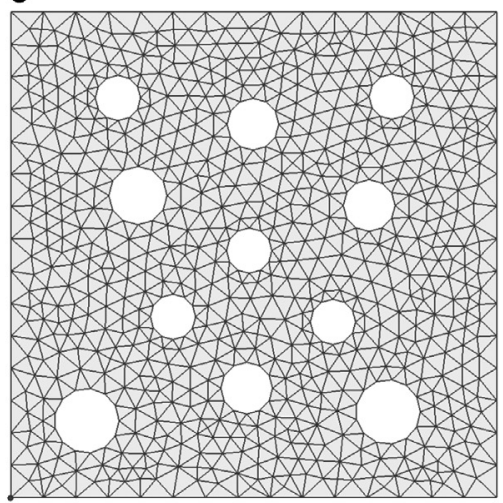

67

68

69

70

71

72

73

74

75

76

77

78

79

80

81

82

d

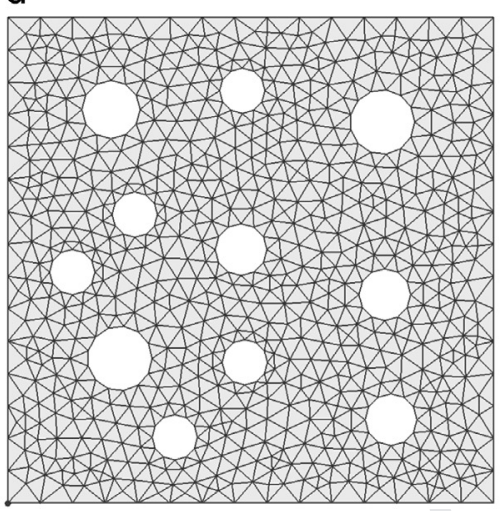

e

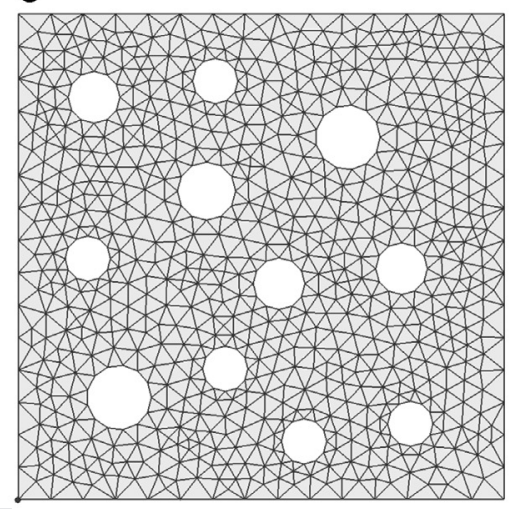

Fig. 12. Different realizations for inclusion volume fraction equal to $10 \%$ and volume element size equal to $15 \mu \mathrm{m}$.

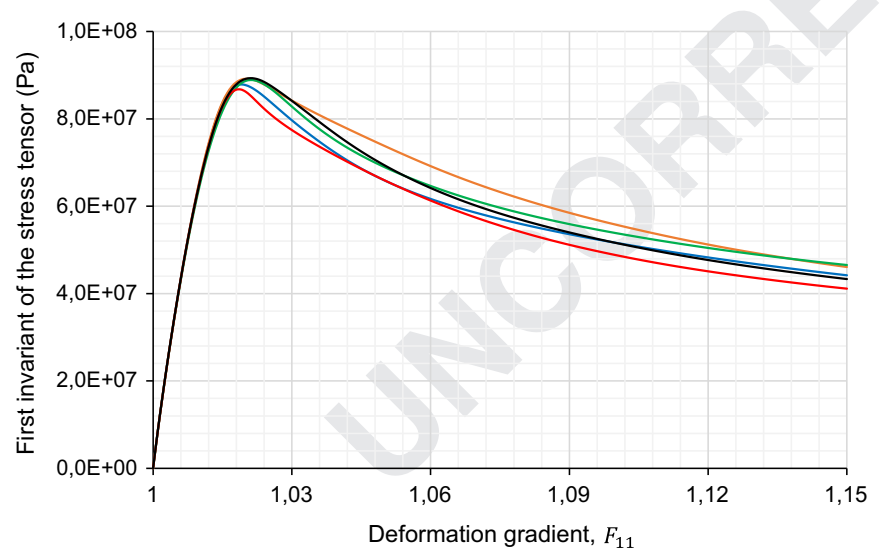

Fig. 13. Stress-deformation of the samples shown in Fig. 12: blue line: Fig. 12(a), orange line: Fig. 12(b), green line: Fig. 12(c), red line: Fig. 12(d), black line: Fig. 12(e) (For interpretation of the references to colour in this figure caption, the reader is referred to the web version of this paper.)

material when the macroscopic stress and strain measures converge.

\subsection{RT-PS with $10 \%$ of rubbery particles}

Fig. 8 shows three micro-structural samples with $10 \%$ of inclusion volume fraction and different sizes namely, $10 \mu \mathrm{m}$, $15 \mu \mathrm{m}$ and $20 \mu \mathrm{m}$.

Remark 3. Preliminary simulations with micro-structural samples smaller than $10 \mu \mathrm{m}$ revealed that the RVE size could not be smaller



Fig. 14. Average stress-deformation of the samples shown in Fig. 12 with shaded bounds of standard deviation.

Table 3

The percentage of (standard deviation/average) for some representative values of deformation gradient for samples shown in Fig. 12.

\begin{tabular}{lllllll}
\hline Deformation gradient, $F_{11}$ & 1,01 & 1,02 & 1,05 & 1,08 & 1,12 & 1,15 \\
\hline Standard deviation/average (\%) & 0.73 & 1.41 & 4.70 & 4.99 & 4.99 & 4.95 \\
\hline
\end{tabular}

than $10 \mu \mathrm{m}$ according to the introduced criteria. Thus, the initial volume element size to start the analysis is chosen to be $10 \mu \mathrm{m}$.

Five different morphologies for inclusion volume fraction equal to $10 \%$ and volume element size equal to $10 \mu \mathrm{m}$ are shown in Fig. 9. For each volume size, a trial and error algorithm is employed
83

84

85

86

87

88

89

90

91

92

93

94

95

96

97

98

99

100

101

102

103

104

105

106

107

108

109

110

111

112

113

114

115

116

117

118

119

120

121

122

123

124

125

126

127

128

129

130

131

132 
a



d

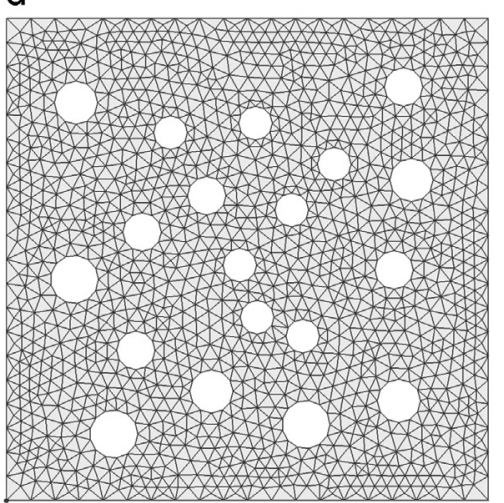

b



C



Fig. 15. Different realizations for inclusion volume fraction equal to $10 \%$ and volume element size equal to $20 \mu \mathrm{m}$.

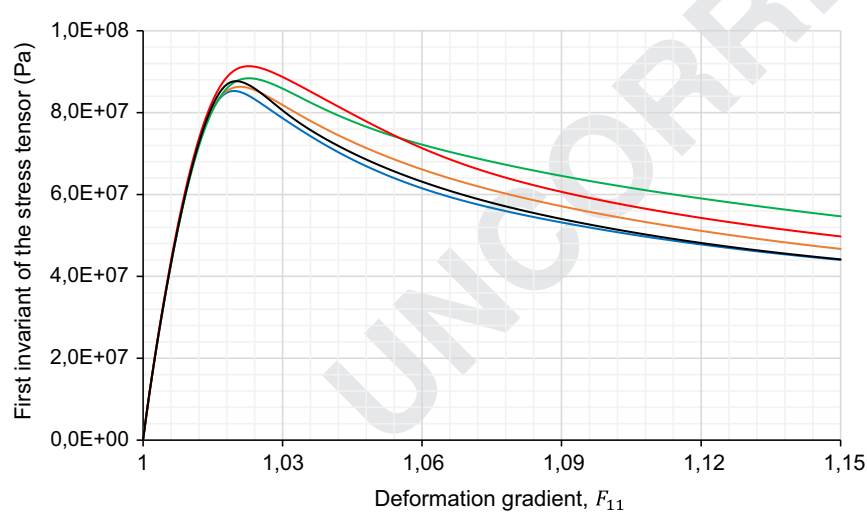

Fig. 16. Stress-deformation of the samples shown in Fig. 15: blue line: Fig. 15(a), orange line: Fig. 15(b), green line: Fig. 15(c), red line: Fig. 15(d), black line: Fig. 15(e). (For interpretation of the references to colour in this figure caption, the reader is referred to the web version of this paper.)

to compute different radii of inclusions, within the range $0.7-1.0 \mu \mathrm{m}$, such that the desired inclusion volume fraction is achieved. This procedure attempted to mimic the process of rubber toughening, which is usually performed using sub-micron sized rubbery particles with different radii. Once the radii of all inclusions for each volume size and volume fraction are defined, five realizations are generated using a random sequential addition algorithm that places the same inclusions within the domain. This strategy guarantees that all realizations have exactly the same inclusion volume fraction.

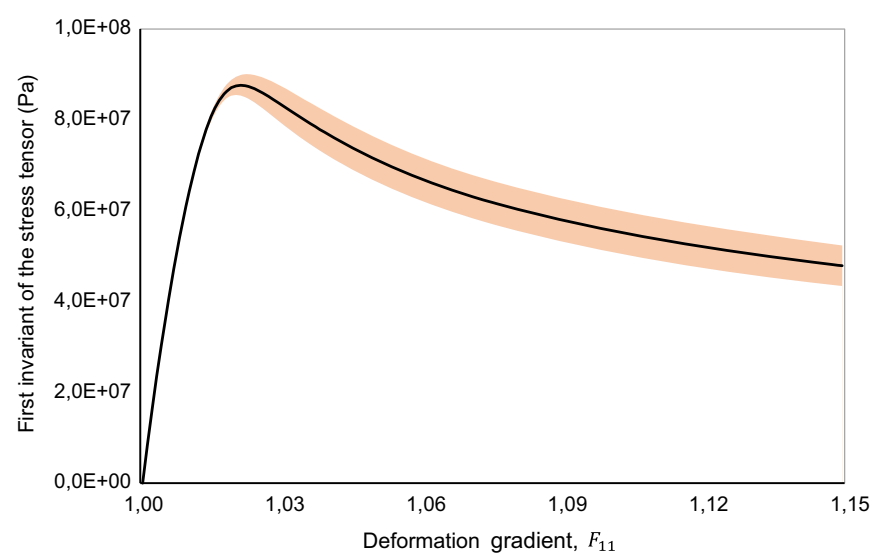

Fig. 17. Average stress-deformation of the samples shown in Fig. 15 with shaded bounds of standard deviation.

Table 4

The percentage of (standard deviation/average) for some representative values of deformation gradient for samples shown in Fig. 15.

\begin{tabular}{lcccccc}
\hline Deformation gradient, $F_{11}$ & 1,01 & 1,02 & 1,05 & 1,08 & 1,12 & 1,15 \\
\hline Standard deviation/average (\%) & 0.85 & 2.28 & 6.76 & 7.86 & 8.99 & 9.33
\end{tabular}

Remark 4. As pointed out by Kanit et al. [24], the RVE size could be associated with the defined precision and also the number of realizations. We considered five realizations for each inclusion 


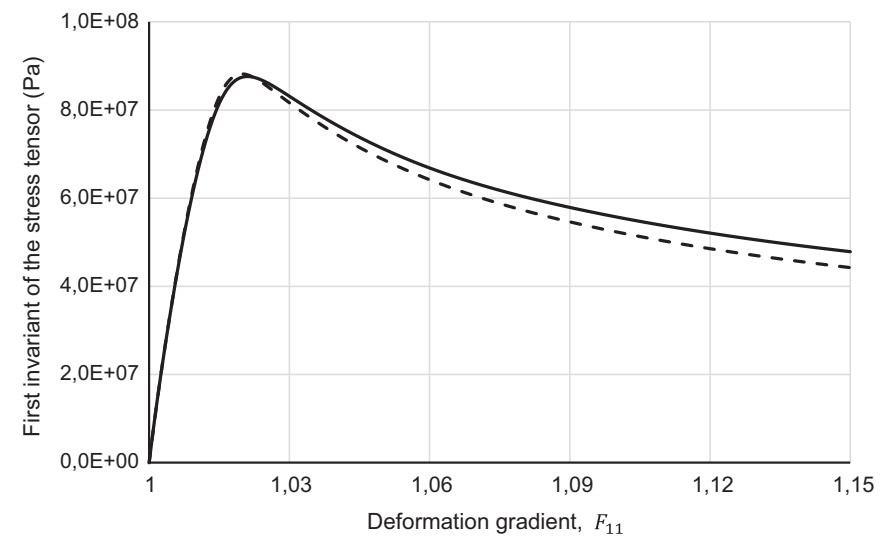

Fig. 18. Average stress-deformation of the samples shown in Figs. 12 and 15. Solid line: volume element size $=20 \mu \mathrm{m}$ and dashed line: volume element size $=15 \mu \mathrm{m}$.

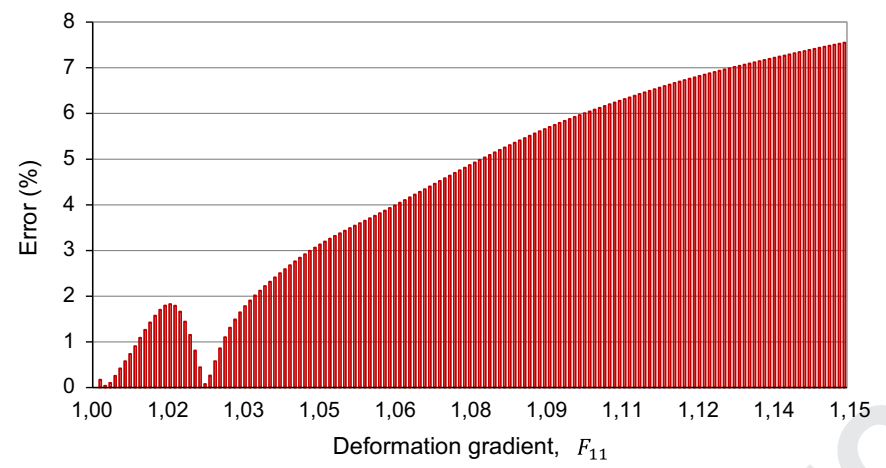

Fig. 19. Difference between the behaviour of samples shown in Figs. 12 and 15.

volume fraction and volume element size, as considered by other authors (see e.g. [28]). Apparently, by increasing the number of samples and also reducing the errors defined above (in the two criteria), more accurate RVE size will be obtained.

Fig. 10 shows stress-deformation curves for different realizations of samples with $10 \%$ of rubbery particles and volume element size equal to $10 \mu \mathrm{m}$. In order to proceed with the determination of the RVES, it is required to check whether or not the first criterion is satisfied. Fig. 11 shows the average response of the samples shown in Fig. 9 together with upper and lower bounds of standard deviation, defined respectively by:

Upper Bound $=\overline{I_{1}(\mathbf{P})}+S_{I_{1}(\mathbf{P})}, \quad$ Lower Bound $=\overline{I_{1}(\mathbf{P})}-S_{I_{1}(\mathbf{P})}$.

In this study, if the standard deviation is within $10 \%$ of the average response, it is considered acceptable. In other words, if the standard deviation of the deformation behaviour, through the whole deformation, is less than $10 \%$ of the average deformation behaviour, the first criterion is satisfied. For the first series of samples with inclusion volume fraction equal to $10 \%$ and volume element size equal to $10 \mu \mathrm{m}$, the first criterion is not satisfied. This means that during the deformation process, the standard deviation is not always less than $10 \%$ of the average deformation behaviour. Table 2 gives the values of the percentage of the standard deviation to the mean value as a function of the deformation gradient at some representative deformation gradients. According to the proposed algorithm, shown in Fig. 7, the next step is to generate samples with the same inclusion volume fraction and a bigger size.
Five different morphologies for inclusion volume fraction equal to $10 \%$ and volume element size equal to $15 \mu \mathrm{m}$ are shown in Fig. 12. The same loading is applied to these realizations and the stress-deformation curves are given in Fig. 13. Fig. 14 shows the average response of the samples depicted in Fig. 12 with the upper and lower bounds of standard deviation. As expected, making a comparison between Figs. 10 and 13 and also between Figs. 11 and 14 shows that by increasing the volume element size from $10 \mu \mathrm{m}$ to $15 \mu \mathrm{m}$, the deformation behaviour of different realizations are closer to each other.

For the samples in Fig. 12, the first criterion is satisfied, i.e. the values of the standard deviation during deformation are less than $10 \%$ of the average behaviour. The values of the standard deviation/average versus deformation gradient are given in Table 3.

The next stage consists in generating bigger samples in order to proceed with the determination of the RVES. Five different realizations with volume element size equal to $20 \mu \mathrm{m}$ are shown in Fig. 15. The respective stress-deformation curves are shown in Fig. 16. Again, it is required to check if the first criterion is satisfied for the samples with volume element size equal to $20 \mu \mathrm{m}$. The average response of the samples shown in Fig. 15 with the bounds of standard deviation are given in Fig. 17. Table 4 shows that the values of standard deviation are within the bounds defined, $10 \%$ of the average. Hence, the second criterion should be checked. In this study, $10 \%$ difference between the average behaviour of two volume element size is allowed. In other words, if the average behaviour of samples with $15 \mu \mathrm{m}$ of volume element size, shown in Fig. 12, are within $10 \%$ difference to the average behaviour of samples with $20 \mu \mathrm{m}$ of volume element size, the second criterion is satisfied too. Fig. 18 shows the average responses of both series of samples. In order to appreciate the evolution of the difference between the two averages, Fig. 19 shows the measure of the difference, i.e. error, between the average behaviour of samples shown in Figs. 12 and 15 versus deformation gradient. In Fig. 19, the error is computed by:

$\operatorname{Error}(\%)=\frac{\left|{\overline{I_{1}(\mathbf{P})}}^{20 \mu \mathrm{m}}-{\overline{I_{1}(\mathbf{P})}}^{15 \mu \mathrm{m}}\right|}{{\overline{I_{1}(\mathbf{P})}}^{20 \mu \mathrm{m}}} \times 100$

According to the values of the average deformation behaviours of the two series of samples and also the defined criteria and algorithm, it can be concluded that for Rubber Toughened Polystyrene (RT-PS) with $10 \%$ of rubbery particles, the size of the Representative Volume Element (RVES) can be considered as $15 \mu \mathrm{m}$.

Remark 5. The rather time consuming and cumbersome RVE size determination process is due to the finite deformations. From Fig. 10, it can be obviously realized that within small deformation, still in the elastic regime, all realizations depict the same behaviour. It can also be perceived that even smaller volume element sizes could be satisfactory for small deformations.

As stated before, the rubbery particles are considered as voids in this study due to the internal cavitation of the particles during tensile deformation. Thus, the material considered here is, in fact, porous PS. It is known that porosity magnifies the post-yield softening of polymers. Considering the stress-deformation curves of the samples with different sizes, Figs. 10, 13 and 16, it is possible to conclude that the differences appear mainly after the elastic domain, during softening. Due to the aforementioned reasons, the RVE size determined is, most likely, a representative size for other loading conditions as well. Therefore, the same methodology could be used to define such size using eventually a more appropriate deformation measure. 
Remark 6. In this study the effect of inclusion size range on the RVES is not studied. Stroeven et al. [29] investigated the effect of particle size distribution on the RVES. They concluded, considering peak load and dissipated energy as driving parameters, that changing particle sizes does not significantly change the RVES.

\subsection{RT-PS with $15 \%$ of rubbery particles}

The next volume fraction of rubbery particles to be considered is 15\%. Fig. 20 shows five different realizations for $15 \%$ inclusion volume fraction and $10 \mu \mathrm{m}$ volume element size. The respective stress-deformation curves are given in Fig. 21. In order to check the first criterion, if the standard deviation is within the $10 \%$ of the average response, Fig. 22 presents the average response of the samples given in Fig. 20 together with the bounds of standard deviation of the samples responses. Table 5 shows the percentage of standard deviation/average through the deformation. The criterion is checked and it is not satisfied. The next stage is to generate samples with the same inclusion volume fraction and a bigger size. Fig. 23 shows five different morphologies for $15 \%$ inclusion volume fraction and $15 \mu \mathrm{m}$ volume element size. Fig. 24 depicts stress-deformation curves for different realizations of samples with $15 \%$ inclusion volume fraction and $15 \mu \mathrm{m}$ volume element size. The average response of the samples presented in Fig. 23 with the bounds of standard deviation is given in Fig. 25. Table 6 gives the values of standard deviation/average through the deformation. The standard deviation of the behaviour of the samples is within the defined $10 \%$ of the average. Samples with volume element size equal to $20 \mu \mathrm{m}$ and inclusion volume fraction equal to $15 \%$ are to be generated in order to check the first and second criterion. Five different morphologies for inclusion volume fraction equal to $15 \%$ and volume element size equal to $20 \mu \mathrm{m}$ are shown in Fig. 26. Fig. 27 depicts the respective stress-deformation curves. Fig. 28 shows the average response of the samples presented in Fig. 26 with the bounds of standard deviation. Table 7 depicts the standard deviation/average for different values of deformation gradient. The first criterion is satisfied for this series of samples too. The second criterion should be checked. Fig. 29 depicts the average response of the samples shown in Figs. 23 and 26.

Fig. 30 shows the difference between the average behaviour of samples depicted in Figs. 23 and 26. Based on the defined factors for determination of the RVES and also considering the values of the average deformation behaviours of the two series of samples, the RVES for Rubber Toughened Polystyrene (RT-PS) with 15\% of rubbery particles could be chosen as $15 \mu \mathrm{m}$.

Remark 7. In this work a finite strain elasto-viscoplastic constitutive model, described in Section 3, is employed to model the non-linear behaviour of Polystyrene (PS). Since the viscoplastic formulation includes rate effects, which implicitly introduce a characteristic length through the viscosity, it acts as a regularization method. Therefore, the phenomenon of localization of strains in a narrow band, while the rest of the material experiences unloading, is attenuated and pathological dependence on mesh discretization is alleviated. To confirm this, some of the microstructural samples in this study were spatially discretized with

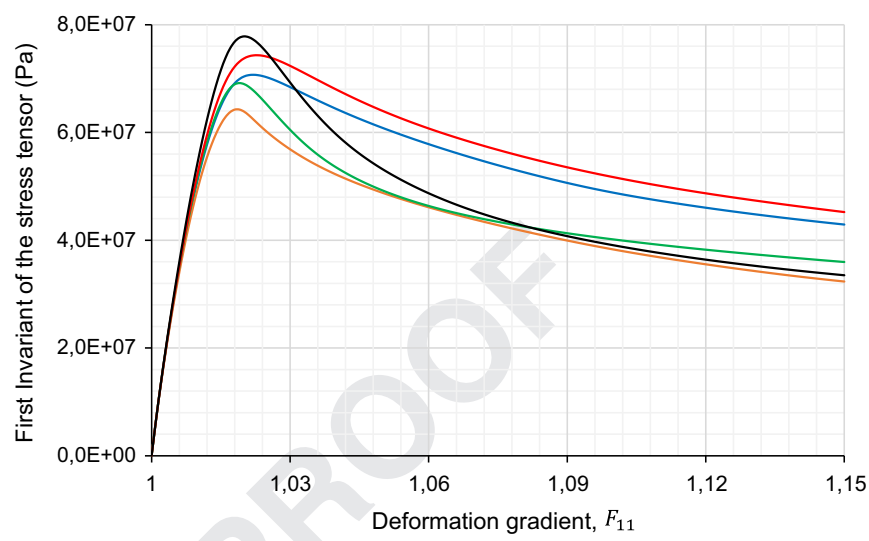

Fig. 21. Stress-deformation of the samples shown in Fig. 20: blue line: Fig. 20(a), orange line: Fig. 20(b), green line: Fig. 20(c), red line: Fig. 20(d), black line: Fig. 20 (e). (For interpretation of the references to colour in this figure caption, the reader is referred to the web version of this paper.)

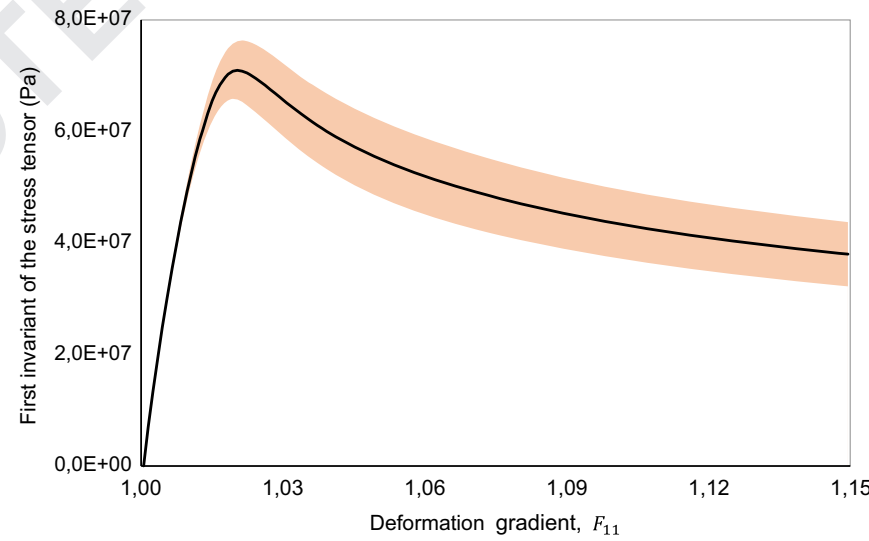

Fig. 22. Average stress-deformation of the samples shown in Fig. 20 with shaded bounds of standard deviation.

Table 5

The percentage of (standard deviation/average) for some representative values of deformation gradient for samples shown in Fig. 20.

\begin{tabular}{lllllll}
\hline Deformation gradient, $F_{11}$ & 1,01 & 1,02 & 1,05 & 1,08 & 1,12 & 1,15 \\
\hline Standard deviation/average (\%) & 3.50 & 7.36 & 12.48 & 13.87 & 14.61 & 15.17
\end{tabular}




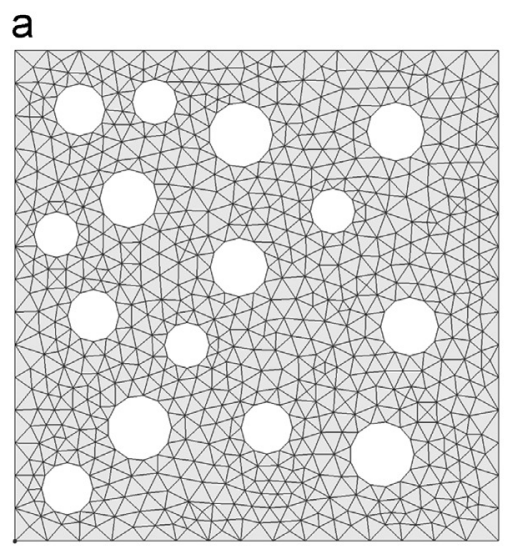

b

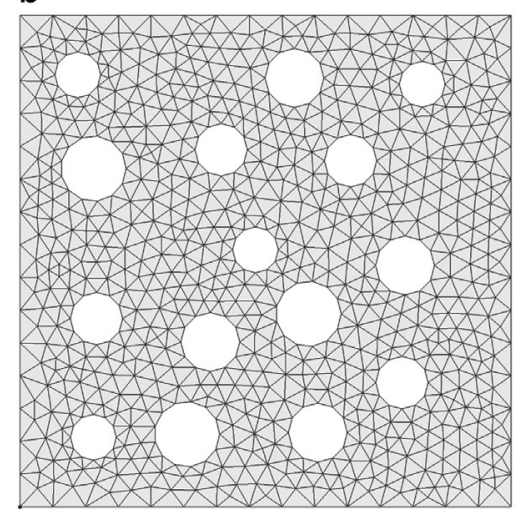

C



67

68

69

70

71

72

73

74

75

76

77

78

79

80

81

82

83

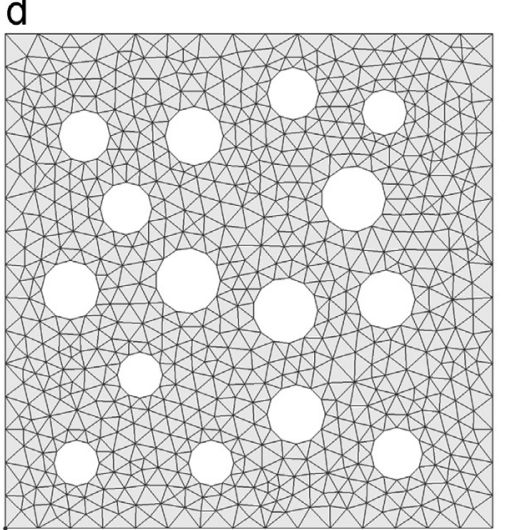

e

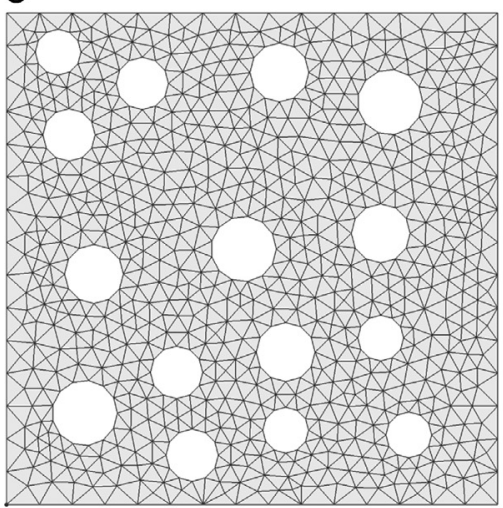

Fig. 23. Different realizations for inclusion volume fraction equal to $15 \%$ and volume element size equal to $15 \mu \mathrm{m}$.

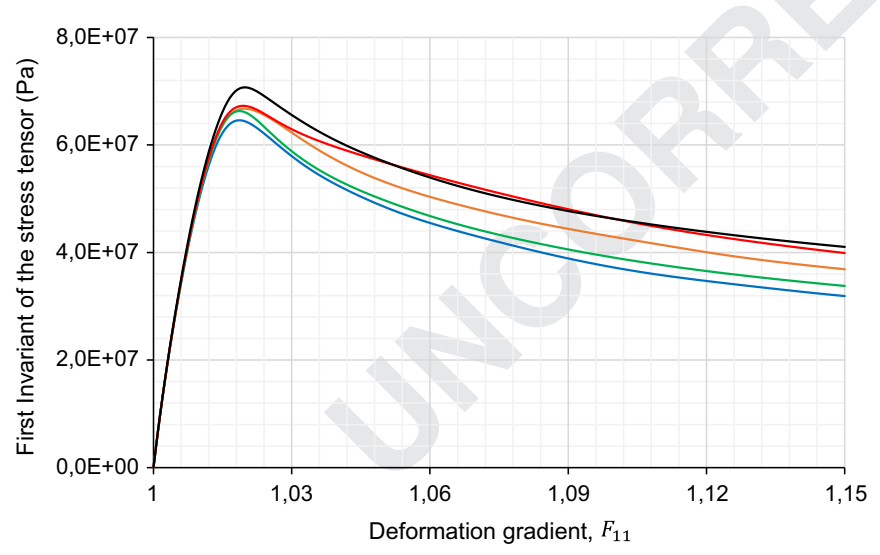

Fig. 24. Stress-deformation of the samples shown in Fig. 23: blue line: Fig. 23(a), orange line: Fig. 23(b), green line: Fig. 23(c), red line: Fig. 23(d), black line: Fig. 23 (e). (For interpretation of the references to colour in this figure caption, the reader is referred to the web version of this paper.)

finer finite element meshes and the difference in the results was negligible.

Remark 8. One may consider more intermediate dimensions, between the considered sizes in this study, to obtain a more precise RVE size.

Remark 9. The authors also applied the two criteria for RVES determination, introduced at the beginning of this section, to the first component of the first Piola-Kirchhof stress tensor $\left(P_{11}\right)$, which is basically the stress component in the loading direction, and similar results (as obtained using the first invariant of the

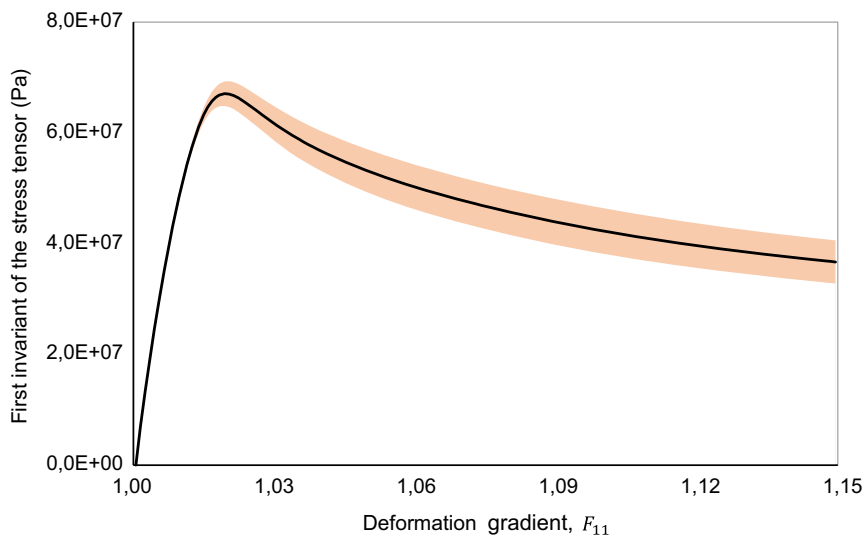

Fig. 25. Average stress-deformation of the samples shown in Fig. 23 with shaded bounds of standard deviation.

Table 6

The percentage of (standard deviation/average) for some representative values of deformation gradient for samples shown in Fig. 23.

\begin{tabular}{lllllll}
\hline Deformation gradient, $F_{11}$ & 1,01 & 1,02 & 1,05 & 1,08 & 1,12 & 1,15 \\
\hline Standard deviation/average (\%) & 1.29 & 3.48 & 6.34 & 7.96 & 9.14 & 9.62 \\
\hline
\end{tabular}

stress tensor) were obtained for both cases of RT-PS with $10 \%$ and $15 \%$ of rubbery particles.

It should be emphasized that the statistical-numerical approach for RVES determination, introduced in this study, has certain 


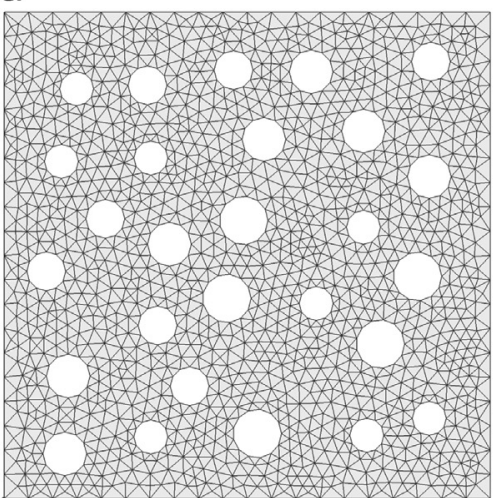

d

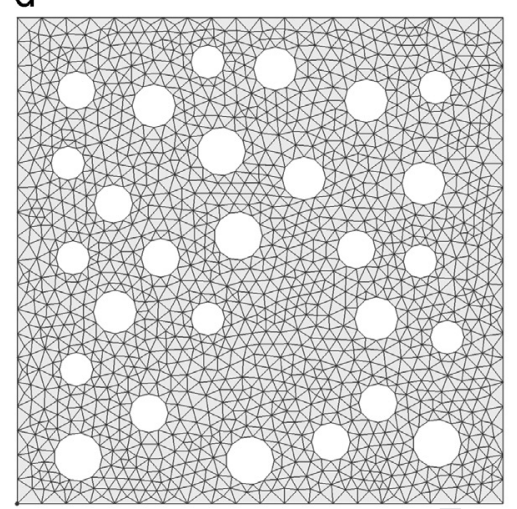

b



C

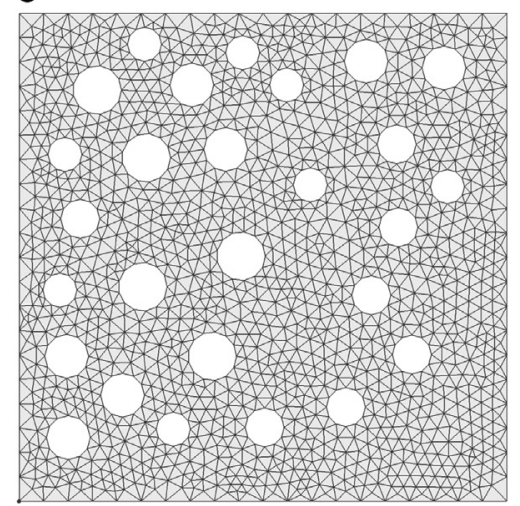

67

68

69

70

71

72

73

74

75

76

77

78

79

80

81

82

83

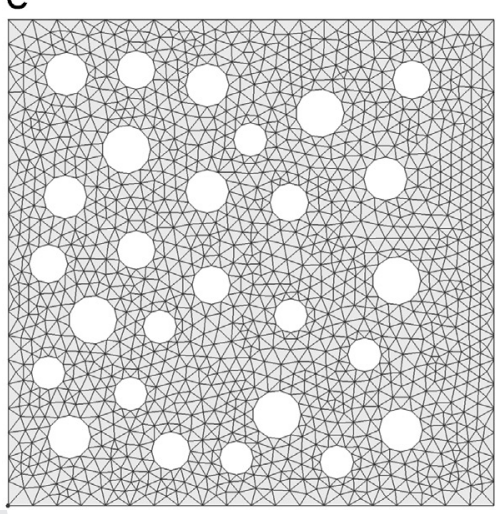

Fig. 26. Different realizations for $15 \%$ inclusion volume fraction and $20 \mu \mathrm{m}$ volume element size.

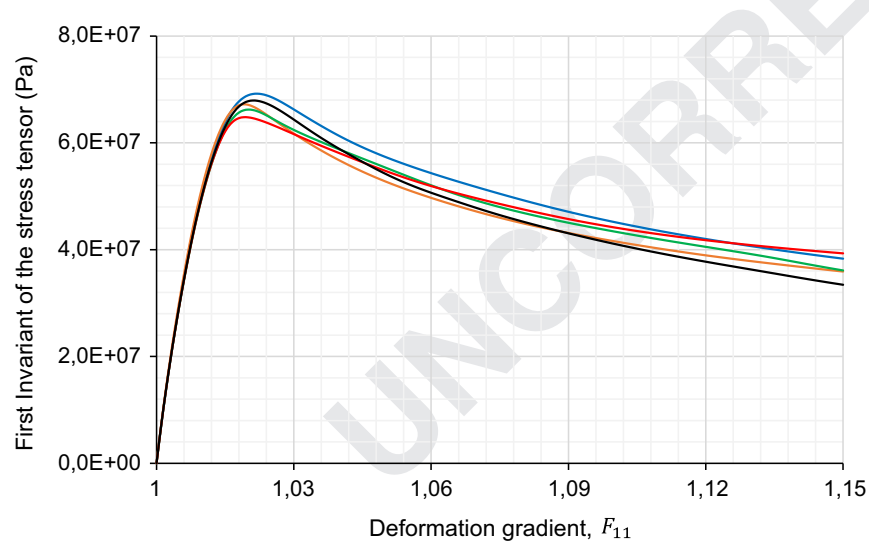

Fig. 27. Stress-deformation of the samples shown in Fig. 26: blue line: Fig. 26(a), orange line: Fig. 26(b), green line: Fig. 26(c), red line: Fig. 26(d), black line: Fig. 26 (e). (For interpretation of the references to colour in this figure caption, the reader is referred to the web version of this paper.)

advantages compared to the previously introduced methods:

- Using this approach it is not required to investigate different regimes of the deformation, namely elastic, yield and softening, separately and thus it facilitates the statistical study.

- All possible criteria (e.g. slope of the graph in different regimes of the deformation, the strain at which the material yields and dissipated energy) are covered using this approach.

Based on the analysis conducted, we conclude that for materials which show a moderate softening response, an RVE size can be determined.

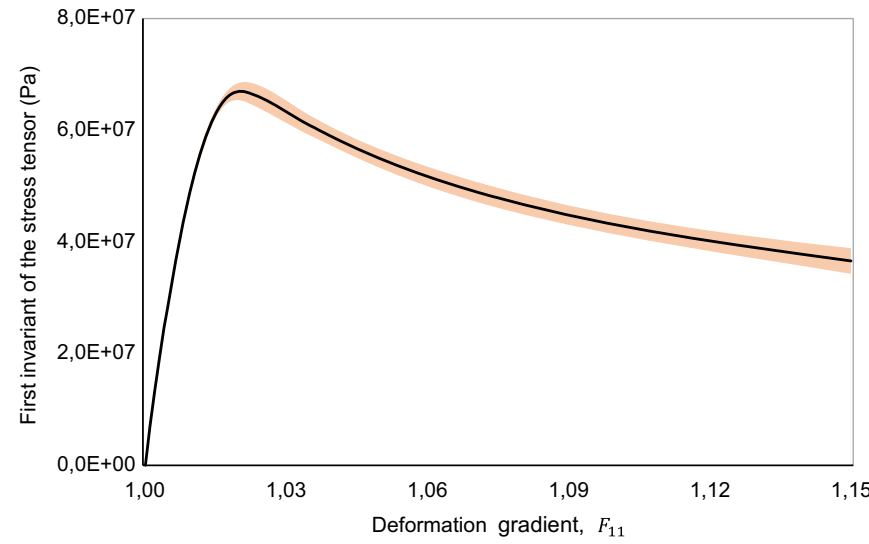

Fig. 28. Average stress-deformation of the samples shown in Fig. 26 with shaded bounds of standard deviation.

Table 7

The percentage of (standard deviation/average) for some representative values of deformation gradient for samples shown in Fig. 26.

\begin{tabular}{lllllll}
\hline Deformation gradient, $F_{11}$ & 1,01 & 1,02 & 1,05 & 1,08 & 1,12 & 1,15 \\
\hline Standard deviation/average (\%) & 1.46 & 2.33 & 3.06 & 3.79 & 4.56 & 6.27 \\
\hline
\end{tabular}

\section{Conclusions}

In this paper, some numerical examples on Rubber Toughened Polystyrene (RT-PS), with two different levels of Inclusion Volume Fraction, were presented. Having different morphologies showed the necessity of determination of the RVE Size. Due to moderate 


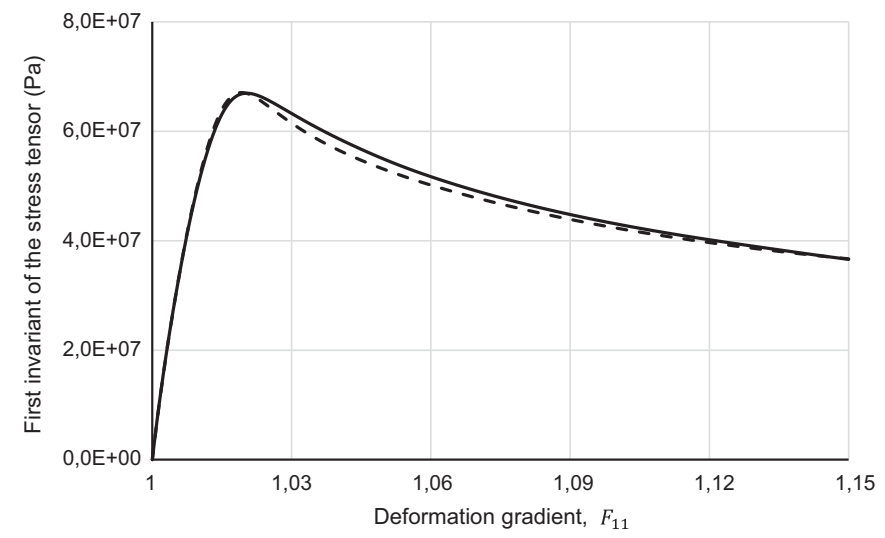

Fig. 29. Average stress-deformation of the samples shown in Figs. 12 and 15. Solid line: volume element size $=20 \mu \mathrm{m}$ and dashed line: volume element size $=15 \mu \mathrm{m}$.

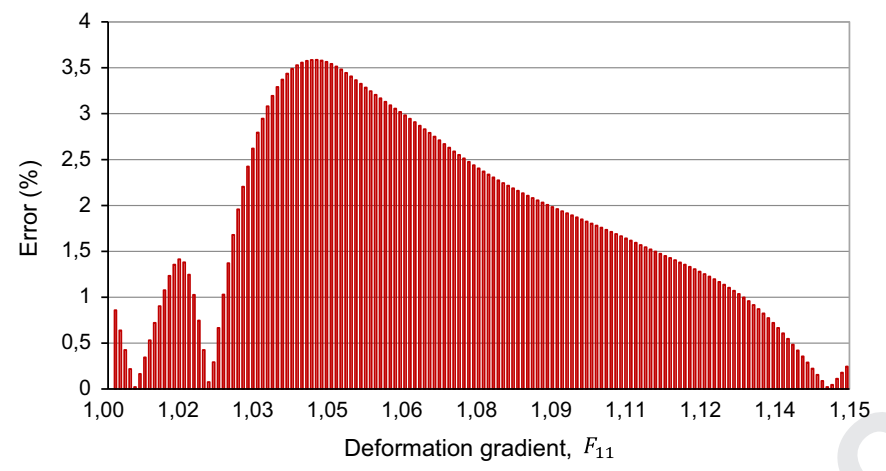

Fig. 30. Difference between the behaviour of samples shown in Figs. 23 and 26.

post-yield softening behaviour of the material, determination of a minimum size for the microstructural samples is of great importance. This fact was shown by increasing the size of the micro-structural samples and observing the difference. According to the factors, commonly used in the definition of the RVE, two criteria were introduced for determination of the RVES. It is worth emphasizing that in case of non-softening materials, determination of the RVES would be much easier due to the fact that softening behaviour causes localization of the deformation and this deformation localization greatly affects the overall deformation behaviour of the material. It was concluded that for both cases of inclusion volume fraction equal to $10 \%$ and $15 \%$, the RVES could be considered $15 \mu \mathrm{m}$. In the future, expanding this statistical analysis with a lager number of samples for each volume element size may lead to further accurate results for the RVES.

\section{Acknowledgements}

The authors acknowledge FCT (Fundação para a Ciência e a Tecnologia), Lisbon, through the 3 Quadro Comunitário de Apoio, the POCTI and FEDER programs, and the grant PTDC-EME-PME108859-2008 (through IDMEC), and the SFRH/BD/74027/2010 PhD scholarship within POPH/FSE (Programa Operacional Potencial Humano/Fundo Social Europeu).

\section{References}

[1] J. Mackerle, Finite element analysis and simulation of polymers an addendum: a bibliography (1996-2002), Model. Simul. Mater. Sci. 11 (2003) 195-231 〈http://iopscience.iop.org/article/10.1088/0965-0393/11/2/307〉.
[2] M. Danielsson, D.M. Parks, M.C. Boyce, Micromechanics, macromechanics and constitutive modeling of the elasto-viscoplastic deformation of rubbertoughened glassy polymers, J. Mech. Phys. Solids 55 (2007) 533-561〈http:// www.sciencedirect.com/science/article/pii/S0022509606001347).

[3] M.C.M. van Der Sanden, H.E.H. Meijer, Ultimate toughness of amorphous polymers, Macromol. Symp. 75 (1993) 115-125 〈http://onlinelibrary.wiley. com/doi/10.1002/masy.19930750111/abstract).

[4] M. Geers, Experimental analysis and computational modelling of damage and fracture, (Ph.D. thesis), Eindhoven University Of Technology, Eindhoven, The Netherlands, 1997. 〈http://www.mate.tue.nl/mate/pdfs/43.pdf .

[5] S. Ghosh, K. Lee, S. Moorthy, Two scale analysis of heterogeneous elasticplastic materials with asymptotic homogenisation and Voronoi cell finite element model, Comput. Methods Appl. Mech. Eng. 132 (1996) 63-116 〈http:// www.sciencedirect.com/science/article/pii/0045782595009744).

[6] R. Smit, W. Brekelmans, H.E.H. Meijer, Prediction of the mechanical behavior of nonlinear heterogeneous systems by multi-level finite element modeling, Comput. Methods Appl. Mech. Eng. 155 (1998) 181-192 〈http://www.science direct.com/science/article/pii/S0045782597001394).

[7] O. Van der Sluis, P.J.G. Schreurs, W. Brekelmans, H.E.M. Meijer, Overall behavior of heterogeneous elastoviscoplastic materials: effect of microstructural modelling, Mech. Mater. 32 (2000) 449-462 〈http://www.sciencedirect.com/ science/article/pii/S0167663600000193).

[8] O. Van der Sluis, P.J.G. Schreurs, H.E.M. Meijer, Homogenization of structured elasto-viscoplastic solids at finite strains, Mech. Mater. 33 (2001) 499-522 〈http://www.sciencedirect.com/science/article/pii/S0167663601000667〉.

[9] B.M. Love, R.C. Batra, Determination of effective thermo-mechanical parameters of a mixture of two elastothermoviscoplastic constituents, Int. J. Plast. 22 (2006) 1026-1061 〈http://www.sciencedirect.com/science/article/pii/S0749641905001270〉.

[10] N. Yong, Y.M. Chiang, Prediction of elastic properties of heterogeneous materials with complex microstructures, J. Mech. Phys. Solids 55 (2007) 517-532 〈http://www.sciencedirect.com/science/article/pii/S0022509606001360〉.

[11] N. Charalambakis, Homogenization techniques and micromechanics: a survey and perspectives, Appl. Mech. Rev. 63 (2010) 030803-1. 〈http://appliedmecha nicsreviews.asmedigitalcollection.asme.org/article.aspx? articleid $=1399665\rangle$.

[12] R. Hill, A self-consistent mechanics of composite materials, J. Mech. Phys Solids 13 (1965) 213-222 〈http://www.sciencedirect.com/science/article/pii/ 0022509665900104>.

[13] W.J. Drugan, J.R. Willis, A micromechanics-based nonlocal constitutive equation and estimates of representative volume element size for elastic composites, J. Mech. Phys. Solids 44 (1996) 497-524 〈http://www.sciencedirect.com/ science/article/pii/0022509696000075).

[14] Z. Hashin, Analysis of composite materials-a survey, J. Appl. Mech. 50 (1983) 481-505 〈http://appliedmechanics.asmedigitalcollection.asme.org/article.aspx? articleid $=1407040\rangle$.

[15] J.G.M. van Mier, Fracture Processes of Concrete, CRC Press, USA, 1996, 〈https:/ www.crcpress.com/Fracture-Processes-of-Concrete/van-Mier/9780849391231〉.

[16] P. Evesque, Fluctuations correlations and representative elementary volume (REV) in granular materials, Poudres Grains 11 (2000) 6-17 〈http://arxiv.org/ ftp/cond-mat/papers/0506/0506385.pdf).

[17] A.M. Freudenthal, The Inelastic Behavior of Engineering Materials and Structures, Wiley, 1950, 〈http://www.worldcat.org/title/inelastic-behavior-of-engi neering-materials-and-structures/oclc/494812708

[18] M. Ostoja-Starzewski, Microstructural randomness versus representative volume element in thermomechanics, J. Appl. Mech. 69 (2002) 25-35〈http://appliedme chanics.asmedigitalcollection.asme.org/article.aspx?articleid $=1414475\rangle$.

[19] Q. Grimal, K. Raum, A. Gerisch, P. Laugier, A determination of the minimum sizes of representative volume elements for the prediction of cortical bone elastic properties, Biomech. Model. Mechanobiol. 10 (2011) 925-937 〈http:// link.springer.com/article/10.1007〉.

[20] Z. Shan, A.M. Gokhale, Representative volume element for non-uniform micro-structure, Comput. Mater. Sci. 24 (2002) 361-379 〈http://www.scien cedirect.com/science/article/pii/S0927025601002579).

[21] S. Graham, N. Yang, Representative volumes of materials based on microstructural statistics, Scr. Mater. 48 (2003) 269-274 〈http://www.sciencedirect. com/science/article/pii/S1359646202003627〉.

[22] P. Romero, E. Masad, Relationship between the representative volume element and mechanical properties of asphalt concrete, J. Mater. Civil Eng. 193 (2001) 77-84 〈http://ascelibrary.org/doi/pdf/10.1061/(ASCE)0899-1561(2001)13〉.

[23] S.K. Sebsadji, K. Chouicha, Determining periodic representative volumes of concrete mixtures based on the fractal analysis, Int. J. Solids Struct. 49 (2012) 2941-2950 〈http://www.sciencedirect.com/science/article/pii/S0020768312002193〉.

[24] T. Kanit, S. Forest, I. Galliet, V. Mounoury, D. Jeulin, Determination of the size of the representative volume element for random composites: statistical and numerical approach, Int. J. Solids Struct. 40 (2003) 3647-3679 〈http://www. sciencedirect.com/science/article/pii/S0020768303001434).

[25] T. Kanit, F. N'Guyen, S. Forest, D. Jeulin, M. Reed, S. Singleton, Apparent and effective physical properties of heterogeneous materials: representativity of samples of two materials from food industry, Comput. Methods Appl. Mech. Eng. 195 (2006) 3960-3982〈http://www.sciencedirect.com/science/article/ pii/S0045782505003889).

[26] C. Pelissou, J. Baccou, Y. Monerie, F. Perales, Determination of the size of the representative volume element for random quasi-brittle composites, Int. J. Solids Struct. 46 (2009) 2842-2855 〈http://www.sciencedirect.com/science/ article/pii/S0020768309001334). 
[27] L. Skarzynski, J. Tejchman, Determination of representative volume element in concrete under tensile deformation, Comput. Concr. 9 (2012) 35-50 〈http:/ technopress.kaist.ac.kr/samplejournal/pdf/cac0901003.pdf).

[28] I.M. Gitman, H. Askes, L.J. Sluys, Representative volume: existence and size determination, Eng. Fract. Mech. 74 (2007) 2518-2534 〈http://www.science direct.com/science/article/pii/S0013794406004772〉.

[29] M. Stroeven, H. Askes, L.J. Sluys, Numerical determination of representative volumes for granular materials, Comput. Methods Appl. Mech. Eng. 193 (2004) 3221-3238 〈http://www.sciencedirect.com/science/article/pii/S0045782504001331〉.

[30] V.P. Nguyen, O.L. Valls, M. Stroeven., L.J. Sluys, On the existence of representative volumes for softening quasi-brittle materials-a failure zone averaging scheme, Comput. Methods Appl. Mech. Eng. 45-48 (2010) 3028-3038.

[31] K. Terada, M. Hori, T. Kyoya, N. Kikuchi, Simulation of the multi-scale convergence in computational homogenization approaches, Int. J. Solids Struct. 37 (2000) 2285-2311 〈http://www.sciencedirect.com/science/article/pii/S0020768398003412〉.

[32] R. Wentorf, R. Collar, M.S. Shephard, J. Fish, Automated modeling for complex woven mesostructures, Comput. Methods Appl. Mech. Eng. 172 (1999) 273-291 〈http://www.sciencedirect.com/science/article/pii/S0045782598002321〉.

[33] Z. Yuan, J. Fish, Toward realization of computational homogenization in practice, Int. J. Numer. Methods Eng. 73 (2007) 361-380 〈http://onlinelibrary. wiley.com/doi/10.1002/nme.2074/abstract).

[34] F.J.P. Reis, F.M.Andrade. Pires, A mortar based approach for the enforcement of periodic boundary conditions on arbitrarily generated meshes, Comput. Methods Appl. Mech. Eng. 274 (2014) 168-191 〈http://www.sciencedirect. $\mathrm{com} /$ science/article/pii/S0045782514000528 .

[35] F.J.P. Reis, F.M. Andrade Pires, An adaptive sub-incremental strategy for the solution of homogenization-based multi-scale problems, Comput. Methods Appl. Mech. Eng. 257 (2013) 164-182 〈http://www.sciencedirect.com/science/ article/pii/S0045782513000078>.

[36] H. Eyring, Viscosity, plasticity, and diffusion as examples of absolute reaction rates, J. Chem. Phys. 4 (1936) 283-295 〈http://scitation.aip.org/content/aip/ journal/jcp/4/4/10.1063/1.1749836

[37] M. Mooney, A theory of large elastic deformation, J. Appl. Phys. 11 (1940) 582 〈http://scitation.aip.org/content/aip/journal/jap/11/9/10.1063/1.1712836〉.

[38] R.N. Haward, G. Thackray, The use of mathematical model to describe isothermal stress-strain curves in glassy polymers, Proc. R. Soc. A 302 (1968) 453-472 〈http://rspa.royalsocietypublishing.org/content/302/1471/453〉.

[39] M.C. Boyce, D.M. Parks, A.S. Argon, Large inelastic deformation of glassy polymers, Part I: rate dependent constitutive model, Mech. Mater. 7 (1988) 15-33 〈http://www.sciencedirect.com/science/article/pii/0167663688900038〉.

[40] F.P.T. Baaijens, Calculation of residual stresses in injection molded products, Rheol. Acta 30 (1991) 284-299 〈http://link.springer.com/article/10.1007〉.
[41] T. Tervoort, R. Smit, W. Brekelmans, L. Govaert, A constitutive equation for the elasto-viscoplastic deformation of glassy polymers, Mech. Time-Depend. Mater. 1 (1998) 269-291 〈http://link.springer.com/article/10.1023〉.

[42] L. Govaert, P. Timmermans, W. Brekelmans, The influence of intrinsic strain softening on strain localization in polycarbonate: modelling and experimental validation, J. Eng. Mater. Technol. 122 (2000) 177-185 〈http://material stechnology.asmedigitalcollection.asme.org/article.aspx?articleid =1426132 .

[43] R. Simões, A.M. Cunha, W. Brostow, Computer simulations of true stress development and viscoelastic behavior in amorphous polymeric materials, Comput. Mater. Sci. 36 (2006) 319-328 〈http://www.sciencedirect.com/sci ence/article/pii/S0927025605001795).

[44] R. Simões, A.M. Cunha, W. Brostow, Molecular dynamics simulations of polymer viscoelasticity: effect of the loading conditions and creep behaviour, Model. Simul. Mater. Sci. 14 (2006) 157-178 〈http://iopscience.iop.org/article/ 10.1088/0965-0393/14/2/003/pdf).

[45] M.C. Araújo, J.P. Martins, S.M. Mirkhalaf, S. Lanceros-Mendez, F.M. Andrade Pires, R. Simoes, Predicting the mechanical behavior of amorphous polymeric materials under strain through multi-scale simulation, Appl. Surf. Sci. 306 (2014) 37-46 〈http://www.sciencedirect.com/science/article/pii/S016943321400600X).

[46] A. Bilby, LR.T. Lardner A.N. Stroh, Continuous distributions of dislocations and the theory of plasticity. In: Actes du IXe congrès international de mècanique appliquèe, Bruxelles, 1956, vol. 8, 1957, pp. 35-44.

[47] E.H. Lee, Elastic-plastic deformation at finite strains, J. Appl. Mech. 36 (1969) 1-6 〈http://appliedmechanics.asmedigitalcollection.asme.org/article.aspx?articleid = 1398837>.

[48] S. Sadik, A. Yavari, On the origins of the idea of the multiplicative decomposition of the deformation gradient, Math. Mech. Solids, in press.

[49] O.A. Hasan, M.C. Boyce, X.S. Li, S. Berko, An investigation of the yield and postyield behaviour and corresponding structure of poly(methyl methacrylate), J. Polym. Sci. Part B: Polym. Phys. 31 (1993) 185-197 〈http://onlineli brary.wiley.com/doi/10.1002/polb.1993.090310207/abstract〉.

[50] S.M. Mirkhalaf, F.M. Andrade Pires, R. Simoes, An elasto-viscoplastic constitutive model for polymers at finite strains: formulation and computational aspects, Comput. Struct. 166 (2016) 60-74 〈http://dx.doi.org/10.1016/j.comp struc.2016.01.002).

[51] R. Smit, Toughness of Heterogeneous Polymeric Systems: a modeling approach, (Ph.D. thesis), Eindhoven University of Technology, Eindhoven, The Netherlands, 1998. 〈http://www.mate.tue.nl/mate/pdfs/47.pdf $\rangle$.

[52] H.G.H. Van Melick, LE. Govaert, H.E.H. Meijer, Localisation phenomena in glassy polymers: influence of thermal and mechanical history, Polymer 44 (2003) 3579-3591 〈http://www.sciencedirect.com/science/article/pii/S0032386103000892〉. 